\title{
Matematik Kaygısı ile Matematik Başarısı Arasındaki İlişki: Bir Meta-Analiz Çalışması
}

\author{
Hakan BAYIRLI*, Mehmet Ertürk GEÇİCI ${ }^{* *}$, Cahit ERDEM ${ }^{* * *}$
}

• Geliş Tarihi: 20.08.2020 • Kabul Tarihi: 23.01.2021 • Çevrimiçi Yayın Tarihi: 08.04.2021

\section{$\ddot{O} \mathbf{z}$}

$\mathrm{Bu}$ araştırmada, Türkiye bağlamında yapılan matematik kaygısı ile matematik başarısı arasındaki ilişkiyi inceleyen çalışmaların sonuçlarının sentezlenerek istatistiksel olarak birleştirilmesi amaçlanmıştır. $\mathrm{Bu}$ amaç doğrultusunda çalışmada meta-analiz yöntemi kullanılarak, matematik kaygısı ile matematik başarısı arasındaki ilişkinin ortalama etki büyüklüğü hesaplanmıştır. Ayrıca bulunan ortalama etki büyüklüğü, öğrenim kademesi ve yayın türü gibi moderatör değişkenler açısından incelenmiştir. Yapılan taramalar ve uygulanan seçim ölçütleri sonucunda 29 çalışmayla meta-analiz süreci yürütülmüştür. Meta-analize dâhil edilen bu çalışmaların toplam örneklem büyüklüğü 25704'tür. Matematik kaygısı ile matematik başarısı arasında var olan ilişkinin ortalama etki büyüklüğü -.363 olarak saptanmıştır. Bulunan bu etki büyüklüğü doğrultusunda matematik kaygısı ve matematik başarısı arasında negatif orta düzey bir ilişki olduğu belirlenmiştir. Etki büyüklükleri öğrenim kademesi ve yayın türü gibi moderatör değişkenler açısından anlamlı bir farkl11ık göstermemiştir.

Anahtar sözcükler: matematik başarısı, matematik kaygısı, öğrenim kademesi, yayın türü.

\section{Atıf:}

Bayırlı, H., Geçici, M. E: ve Erdem, C. (2021). Matematik kaygısı ile matematik başarısı arasındaki ilişki: bir meta-analiz çalışması. Pamukkale Üniversitesi Eğitim Fakültesi Dergisi, 53, 87109. doi: 10.9779/pauefd.783083.

\footnotetext{
* Arş. Gör., Afyon Kocatepe Üniversitesi, Sınıf Eğitimi Anabilim Dalı, Afyonkarahisar, Türkiye, hbayirli@aku.edu.tr, ORCID ID: https://orcid.org/0000-0002-8415-5418

** Arş. Gör., Afyon Kocatepe Üniversitesi, Matematik Eğitimi Anabilim Dalı, Afyonkarahisar, Türkiye, megecici@aku.edu.tr, ORCID ID: https://orcid.org/0000-0002-5250-1419

*** Dr. Öğr. Üyesi, Afyon Kocatepe Üniversitesi, İngiliz Dili Eğitimi Anabilim Dalı, Afyonkarahisar, Türkiye, cerdem@aku.edu.tr, ORCID ID: https://orcid.org/0000-0001-6988-8122
} 


\section{Giriş}

Matematik, akademik disiplinlerin içinde objektif ve mantığa dayanan bir bilim dalıdır. Bununla birlikte, matematiksel düşünmenin sadece mantığa dayanan bir akı1 yürütme olmadığı, aynı zamanda duyuşsal faktörlerden de önemli düzeyde etkilendiği yaygın olarak kabul edilmektedir (Hannula, 2014). Duyuşsal faktörler, bilişsel faktörler gibi öğrencilerin kariyer planlamalarında matematiği nası kullanacaklarını ve matematiğe nasıl yaklaşacaklarını etkilemektedir (Dede, 2016). Benzer şekilde birçok araştırmacı matematik eğitiminde duyuşsal davranışların önemli bir rolü olduğunu vurgulamıştır (Fennema ve Sherman, 1976; Lee ve Brophy, 1996; McLeod, 1992).

Öğrencilerin duyuşsal alan ile ilgili becerileri tutum, ilgi, güdülenme, öz-yeterlik, özdüzenleme, inanç, kayg1, değer gibi birçok faktörden oluşmaktadır (Ashcraft, 2002; Fennema ve Sherman, 1976; Hannula, 2014; McLeod, 1992; Pajares ve Graham, 1999; Pajares ve Miller, 1994; Schunk, 1991, 2005). Sar1 ve Ekici (2018), PISA ve TIMSS gibi uluslararası sınavlarda yüksek başarı elde eden ülkelerin verilerini incelemişler ve sonuç olarak öğrencilerin başarılarını etkileyen en önemli faktörlerden biri olarak duyuşsal değişkenlere işaret etmişlerdir. Bunun yanında öğrencilerin kaygı, tutum ve motivasyon gibi duyuşsal özelliklerinin matematik başarısı ile çok kuvvetli ilişkilere sahip olduğu ifade edilmektedir (Lim ve Chapman, 2015).

McLeod (1992) matematik kaygısının diğer duyuşsal alanlar içinde en çok ilgi gören alan olduğunu düşünmektedir. Bununla birlikte, matematik kaygısının genel olarak öğrencilerin gerginlik, çaresizlik, sevmeme, endişe ve korku gibi matematik derslerinde sergilediği yoğun duygularla ilişkili bir yapı olduğunu da vurgulamaktadır (McLeod, 1992). Baloğlu ve Koçak (2006) ise kaygının matematikle ilişkili en yaygın sorunlardan biri olduğunu ifade etmektedirler. Peker ve Ertekin (2011) de kayg1 sorununu öğrencilerin matematik derslerinde başarısız olmalarının duyuşsal nedenlerinden biri olarak görmektedirler. Yapılan araştırmalarda da matematik kaygısının bireylerin matematik başarılarını olumsuz etkilediği ortaya konmuştur (Hembree, 1990; Ma, 1999; Namkung, Peng ve Lin, 2019; Peker ve Şentürk, 2012; Ramirez, Gunderson, Levine ve Beilock, 2013; Sarı ve Ekici, 2018; Şad, Kış, Demir ve Özer, 2016; Zhang, Zhao ve Kong, 2019).

Matematik kaygısına ilişkin ilk araştırmalar 1950’li yıllar itibariyle öğretmenlerin gözlemleri ile başlamış fakat 1970'li yıllara kadar eğitim araştırmalarında kendine yer bulamamıştır (Yetgin ve Kara, 2018). 1970'li yıllardan günümüze uzanan süreçte ise matematik kaygısına yönelik birçok araştırmanın yapıldığı görülmektedir (Ashcraft, 2002; 
H. Bayırl1, M.E. Geçici ve C. Erdem / Pamukkale Üniversitesi Eğitim Fakültesi Dergisi, 53, 87-109, 202189 Aydın ve Keskin, 2017; Gürbüz ve Yıldırım, 2016; Hacıömeroğlu, 2019; Hembree, 1990; Hoffman, 2010; Kaba ve Şengül, 2018; Ma, 1999; McLeod, 1992; Mutodi ve Ngirande, 2014; Peker ve Şentürk, 2012; Ramirez ve diğerleri, 2013).

Peker ve Şentürk (2012), matematik kaygısının ilkokul yıllarından üniversite yıllarına kadar uzandığını ifade etmektedirler. Benzer şekilde, Sırmacı (2007) matematiğin anlaşılamamasının yarattığı kaygı sonucunda ilköğretimin ilk yıllarında matematiğe karşı olumsuz tutum geliştiğini ve bunun sonucunda öğrenmenin gecikmekte veya istenilen düzeyde gerçekleşmediğini vurgulamaktadır. Matematik kaygısının öğrenciyi akademik açıdan etkilemesinin yanı sıra insanlarda günlük hayatta matematiğin kullanılmasını gerektiren hesap yapma, para sayma vb. işlemlerde de gerginliğe yol açmaktadır (Richardson ve Suinn, 1972).

Diğer yandan matematik kaygısı öğrencilerin meslek seçimi ve gelecek planlarını da etkileyecek birçok sonuç oluşturmaktadır (Hembree, 1990). Toptaş ve Gözel (2018), matematik kaygısını, matematik öğrenmeyi önemli düzeyde engelleyen, matematiğe karşı olumsuz tutumlar geliştirilmesine sebep olan ve uzun süredir devam eden problemlerden biri olarak öne çıktığını belirtmişılerdir. Dolayısıyla bu alanda yapılan çalışmaları dikkate almanın matematik öğretimine katkı sunacağı ifade edilebilir.

Alanyazın incelendiğinde farklı zaman dilimlerinde matematik kaygısı ile ilgili birtakım meta-analiz çalışmalarının yapıldığı görülmektedir (Hembree, 1990; Ma, 1999; Namkung ve diğerleri, 2019; Şad ve diğerleri, 2016; Zhang ve diğerleri, 2019). Bu çalışmalarda öncelikli olarak matematik kaygısının matematik başarısıyla ilişkisi araştırılmıştır. Hembree (1990) 151 çalışmanın sonuçlarını analiz ederek yapmış olduğu çalışmada, matematik kaygısı ve matematik başarısı arasında orta düzeyde negatif yönlü ( $r=-.34)$ bir ilişki olduğunu belirlemiştir. Diğer yandan Ma (1999), incelediği 26 çalışmaya ait 37 etki büyüklüğü hesaplamış ve matematik kaygısı ile matematik başarısı arasında düşük düzeyde negatif $(r=-.27)$ bir ilişki olduğu sonucuna ulaşmıştır.

Şad ve diğerleri (2016), Türkiye bağlamında ele aldıkları meta-analiz çalışmalarında 2005-2014 yılları arasında yapılan 11 araştırmayı incelemişlerdir. Araştırmanın sonucunda matematik başarısı ve matematik kaygısı arasında orta düzeyde negatif ( $r=-.44)$ bir ilişki olduğu bulunmuştur. Öğrenim kademeleri için yapılan moderatör analizinde ise hem ortaokul $(r=-.49)$ hem de lise $(r=-.34)$ öğrencileri için negatif yönde ve orta düzeyde ilişki hesaplanmıştır. Etki değerlerine ilişkin yapılan karşılaştırmada, matematik başarısı ve matematik kaygısı arasında saptanan ters ilişkinin ortaokul öğrencilerini lise öğrencilerine 
90 H. Bayırl, M.E. Geçici ve C. Erdem / Pamukkale Üniversitesi Eğitim Fakültesi Dergisi, 53, 87-109, 2021

göre daha yüksek düzeyde etkilediği ifade edilmiştir. Bir diğer meta-analiz çalışmasında Zhang ve diğerleri (2019) iki değişken arasında negatif bir ilişki $(r=-.32)$ tespit etmişlerdir. Namkung ve diğerleri (2019) ise benzer şekilde matematik kaygısı ile matematik performansı arasında negatif yönde bir ilişki $(r=-.34)$ olduğu sonucuna ulaşmışlardır. Matematik kaygısı ile ilgili yapılan tüm bu meta-analiz çalışmaları incelendiğinde matematik kaygısının matematik başarısını olumsuz yönde etkilemesi ortak bir sonuç olarak belirtilebilir. $\mathrm{Bu}$ olumsuzluğun etki düzeyi ise çalışmadan çalışmaya farklılık göstermektedir.

Türkiye'de son yıllarda ele alınan bu iki değişken arasındaki ilişkisi üzerine yapılan birçok çalışma olması (Bakan-Kalaycığlu, 2015; Bozkurt, 2012; Dursun ve Bindak, 2011; İlhan ve Öner-Sünkür, 2012, 2013; Kesici, 2015; Kılıç, 2011; Külünk-Akyurt, 2019; Mutlu, Söylemez ve Yasul, 2017; Peker ve Şentürk, 2012; Reçber, 2011; Sarı̈öl, 2019; Temel, 2018) dikkat çekicidir. Farklı örneklemler ile yapılan bu çalışmalardan elde edilen farklı sonuçların güncel meta-analiz çalışmaları ile daha kapsamlı bir şekilde ele alınmasının ilgili alanyazına katkı sağlayacağı düşünülmektedir.

\section{Araştırmanın Amacı}

Bu araştırmada, Türkiye'de matematik kaygısının matematik başarısı ile ilişkisini inceleyen çalışmaların sonuçlarının sentezlenerek istatistiksel olarak birleştirilmesi amaçlanmıştır. Meta-analiz yöntemi kullanılarak yürütülen bu araştırma ile matematik kaygısı ve matematik başarısı arasındaki ilişki konusunda daha geniş kapsamlı bir sonucun elde edileceği düşünülmektedir. Bu amaç doğrultusunda araştırma soruları şu şekilde belirlenmiştir:

1. Öğrencilerin matematik kaygısı ile matematik başarıları arasındaki ilişkinin ortalama etki büyüklüğü nedir?

2. Öğrencilerin matematik kaygısı ile matematik başarıları arasındaki ilişkinin etki büyüklükleri öğrenim kademelerine ve yayın türlerine göre anlamlı bir farklılık göstermekte midir?

\section{Yöntem}

\section{Araştırma Modeli}

Meta-analiz, bulguları birleştirme amacıyla bireysel çalışmalarda saptanan geniş bir analiz bulguları koleksiyonunun istatistiksel olarak ifade edilmesini içerir (Glass, 1976). Çalışmada, matematik kaygısıyla matematik başarısı arasındaki ilişkiyi inceleyen bağımsız 
H. Bayırlı, M.E. Geçici ve C. Erdem / Pamukkale Üniversitesi Eğitim Fakültesi Dergisi, 53, 87-109, 202191 çalışmalardan elde edilen bulguların etki büyüklüğü meta-analiz yöntemi ile hesaplanmıştır. Meta-analiz yöntemi literatür tarama yöntemlerinden farklı olarak, hipotezler oluşturan ve oluşturulan hipotezlerin doğruluğunu test etmek için istatistiksel tekniklere ve sayısal verilere ihtiyaç duyan bir nicel araştırma yöntemidir (Durlak ve Lipsey, 1991).

Meta-analiz çalışmasında, araştırmacının belirlediği ölçütlere uygun olan çalışmalar araştırmacı tarafından kodlanır. Farklı araştırmacıların yaptıkları bağımsız çalışmaları karşılaştırmak amacıyla veri toplama araçları, verilerin analizi ve doğal olarak ölçüm sonuçları birbirinden farklı olan çalışmaların bulguları standart olarak ifade edilmelidir. $\mathrm{Bu}$ işlemler sonucunda bağımsız araştırmalardan elde edilen etki büyüklükleri sentezlenerek ortak bir etki değerine ulaşılır (Yıldırım, 2014).

\section{Çalışma Örneklemi ve Seçim Ölçütleri}

Meta-analizde yer verilecek olan çalışmaların belirlenebilmesi için Yüksek Öğretim Kurumu Tez Merkezi, Google Scholar ve TR Dizin veri tabanları taranarak ilgili çalışmalara ulaşılmıştır. $\mathrm{Bu}$ araştırmaya dâhil edilecek araştırmaları belirleyebilmek için tarama sırasında Türkçe olarak "kaygı”, “matematik kaygısı" ve "başarı", İngilizce olarak ise "anxiety", "math anxiety" ve "achievement" gibi anahtar kelimeler kullanılmıştır. Yukarıda belirtilen veri tabanlarında anahtar kelimelere uygun şekilde yapılan taramalar sonucunda 68 makale 82 tez olmak üzere toplamda 150 çalışmaya ulaşılmıştır. Son tarama işlemi 5 Mayıs 2020 tarihinde yapılmıştır. Hangi çalışmaların meta-analizinin yapılacağına karar verme aşamasında aşağıdaki ölçütler temel alınmıştır:

1. Matematiğe yönelik kaygı ile matematik başarısı arasındaki ilişkiye yönelik korelasyonel bir çalışma olması,

2. Çalışmaların; örneklem büyüklüğü, p ve r gibi istatistiksel değerlere sahip olması,

3. Çalışmaların Türkiye'de yayımlanmış olması,

4. Çalışma dilinin Türkçe veya İngilizce olması.

Yapılan taramalar ve uygulanan ölçütler sonucunda 29 çalışmayla meta-analiz süreci yürütülmüştür. Matematik kaygısı ve matematik başarısı arasındaki ilişkiyi inceleyen 29 çalışmadan 20'si tez, 9'u ise makale türünde çalışmalardır. Bazı tez çalışmalarından ise makale üretildiği görülmüştür. Bu şekildeki çalışmalar için sadece tezler meta-analize dâhil edilmiştir. 


\section{Kodlama İşlemi ve Çalışma Karakteristikleri}

Meta-analiz kapsamında analiz edilen çalışmaların etki büyüklüklerini karşılaştırmak için araştırmalara ait bilgiler sınıflandırılıp kodlanmıştır. Kodlama yapılırken oluşturulan formda aşağıdaki gibi başlıklar oluşturulmuştur:

- Yazarlar

- Yayın türü

- Öğrenim kademesi

• Örneklem büyüklüğü

- Korelasyon katsayıs1

Kodlama işlemi 2 uzman tarafından gerçekleştirilmiştir. Yapılan kodlama işlemi sonucunda meta-analizde yer verilen çalışmaların özellikleri Tablo 1'de verilmiştir.

Tablo 1. Meta-analizde yer alan çalışmaların karakteristik bilgileri

\begin{tabular}{|c|c|c|c|c|}
\hline Yazarlar & $\begin{array}{l}\text { Yayın } \\
\text { Türü }\end{array}$ & $\begin{array}{l}\text { Öğrenim } \\
\text { Kademesi }\end{array}$ & $\begin{array}{c}\text { Örneklem } \\
\text { büyüklüğü }(n)\end{array}$ & $\begin{array}{c}\text { Korelasyon } \\
\text { Katsayisı }(r)\end{array}$ \\
\hline Erol, 1989 & Tez & Lise & 375 & -.43 \\
\hline Yenilmez ve Özabac1, 2003 & Makale & Lise & 408 & -.37 \\
\hline Arıkan, 2004 & Tez & Ortaokul & 1130 & -.49 \\
\hline Nazlıçiçek, 2007 & Tez & Lise & 348 & -.39 \\
\hline Sezgin, 2007 & Tez & Lise & 92 & -.37 \\
\hline Akgül, 2008 & Tez & Ortaokul & 292 & -.59 \\
\hline Bekdemir, 2009 & Makale & Üniversite & 95 & -.51 \\
\hline Kalın, 2010 & Tez & Ortaokul & 99 & -.84 \\
\hline Şentürk, 2010 & Tez & Ortaokul & 510 & -.38 \\
\hline Dursun ve Bindak, 2011 & Makale & Ortaokul & 266 & -.58 \\
\hline
\end{tabular}


Y1ldırım, 2011

Makale

Lise

Tez Ortaokul

Tez Ortaokul

Tez Ortaokul

Bozkurt, 2012

İlhan ve Öner-Sünkür, 2012

İlhan ve Öner-Sünkür, 2013

Bakan-Kalaycığglu, 2015

Kesici, 2015

Koza-Çiftçi, 2015

Pekdemir, 2015

Y1lmaz, 2015

Karl1-Şentürk, 2016

Delioğlu, 2017

Mutlu ve diğerleri, 2017

Baban, 2018

Çetiner, 2018

Temel, 2018

Külünk-Akyurt, 2019

Sarıgöl, 2019
Makale Ortaokul

Makale

Ortaokul

Lise

Tez Ortaokul

Makale Ortaokul

Tez

Lise

Tez Ortaokul

Lise

Tez

Tez

Ortaokul

314

.48

Makale İlkokul

474

$-.54$

Tez Ortaokul

463

$-.41$

Tez Ortaokul

351

.51

Tez Ortaokul

176

Tez İlkokul

343

.27

Tez Ortaokul

335

Tablo 1'e göre matematik kaygısı ve matematik başarısı arasındaki ilişkiye sahip olan çalışmalar incelendiğinde; 8 çalışmanın örnekleminin lise kademesinde, 18 çalışmanın ortaokul kademesinde, 2 çalışmanın ilkokul kademesinde, 1 çalışmanın ise üniversite 
kademesinde öğrenim gördüğü anlaşılmaktadır. Bunun yanında meta-analiz çalışmasında yer alan araştırmaların toplam örneklem büyüklüğünün 25704 katılımcıdan oluştuğu tespit edilmiştir. Yapılan çalışmaların 1989 yılından başlayarak günümüze kadar uzandığı görülmektedir. Son yıllarda ise bu konuda yapılan çalışmaların sayıca fazlalaştı̆̆ söylenebilir.

\section{Etki Büyüklüğü Analizi}

Çalışmada, araştırmacılar tarafından belirlenen kriterlere uygun çalışmaların meta-analizini gerçekleştirmek amacıyla Comprehensive Meta Analysis (CMA) yazılımından faydalanılmıştır. Meta-analiz sürecinde ortalama etki büyüklüğünü yorumlamak amacıyla sabit etkiler modeli ve rassal etkiler modeli kullanılmaktadır (Borenstein, 2009). Bu tür çalışmalarda etki büyüklüğünü belirlemek için sabit ve rassal etkiler modelinden hangisinin kullanılacağına karar vermek amacıyla çalışmalar arasındaki heterojenliğe bakılır (Üstün ve Eryılmaz, 2014). Çalışmanın heterojenlik testinin sonuçlarına Tablo 2 'de yer verilmiştir.

Tablo 2. Çalışmanın heterojenlik testi sonuçları

\begin{tabular}{cccc}
\hline Homojenlik Değeri $(Q)$ & Serbestlik Derecesi $(d f)$ & $I^{2}$ & $p$ \\
\hline 956.981 & 28 & 97.07 & .000 \\
\hline
\end{tabular}

Yapılan heterojenlik testi sonucunda, matematik kaygısı ve matematik başarısı çalışmaların etki büyüklükleri istatistiksel olarak anlamlı bulunmuştur. Heterojenlik testinde $p$ değerinin .05'ten küçük olması meta-analiz uygulamasının heterojen bir yapıda olduğunu gösterir ve bu durumda rassal etkiler modelinin kullanılması gerekir (Dinçer, 2014, s. 47). Diğer yandan, matematik kaygısı ve matematik başarısı meta-analizi için $I^{2}$ değeri \%97.07 gibi yüksek düzey heterojenlik oranı bulunmuştur. $I^{2}$ değerinin $\% 75$ ve üzeri olması heterojenliğin düzeyinin yüksek olduğunu göstermektedir (Cooper, Hedges ve Valentine, 2009). Bu sebeple çalışmada matematik kaygısı ile matematik başarısı arasındaki ilişkiye ait etki büyüklüklerinin hesaplanması için rassal etkiler modeli kullanılmıştır.

\section{Yayım Yanlılı̆̆ı}

Meta-analiz çalışmalarındaki en büyük endişelerden biri meta-analitik veri setini oluşturan çalışmaların basılı çalışmalardan oluştuğu, dergilerin anlamlı olmayan sonuçlara sahip çalışmaları reddetme eğiliminde olduğu, basılı çalışmaların ise genellikle aynı yönlü sonuçlar verdiği yani yayım yanlılığına sahip olduğu düşünülerek analiz sonucunda ulaşılan 
H. Bayırlı, M.E. Geçici ve C. Erdem / Pamukkale Üniversitesi Eğitim Fakültesi Dergisi, 53, 87-109, 202195 etki büyüklüğünün yanlı çıkma varsayımıdır (Bakioğlu ve Özcan, 2016; Üstün ve Eryılmaz, 2014). Çalışmaya dâhil edilen araştırmaların yayım yanlılığının tespit edilmesi amacıyla öncelikle Huni Saçılım Grafiği yöntemi kullanılmış ardından “Rosenthal ve Orwin'in Klasik Güvenli N”, ile “Egger'in Doğrusal Regresyon Testi” yöntemleri kullanılmıştır. Matematik kaygısı ve matematik başarısı ilişkisine ait huni saçılım grafiği Şekil 1'de sunulmuştur.

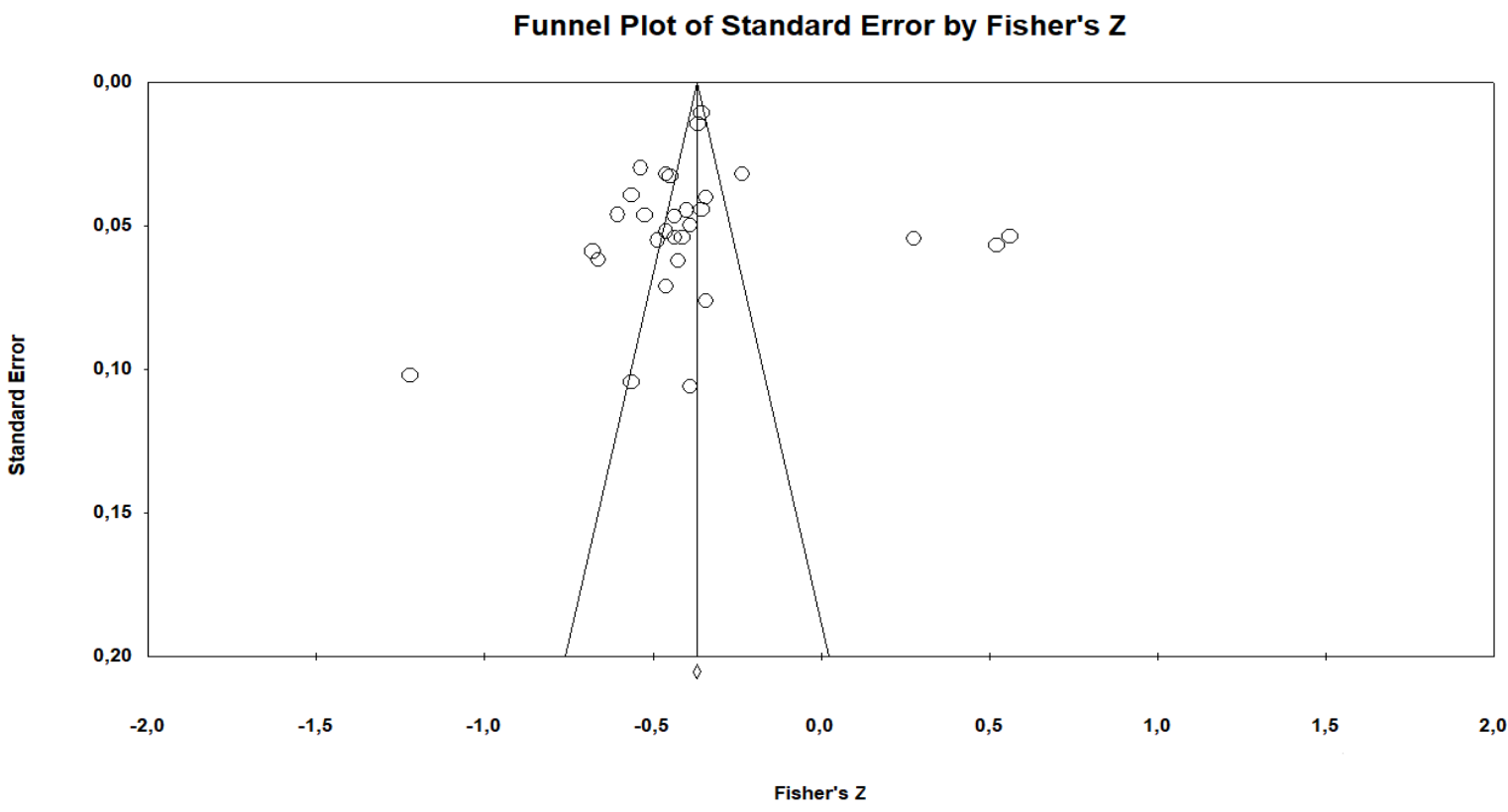

Şekil 1. Veri setindeki çalışmaların etki büyüklüklerine ilişkin huni grafiği

Şekil 1'e göre meta-analize dâhil edilen çalışmaların çoğunun huni grafiğinin orta ve iç kısmında toplandığı görülmüştür. Meta-analiz kapsamındaki yayınların etki büyüklüklerinin genel etki büyüklüğünü ifade eden çizginin sol kısmında toplandığı söylenebilir. Bir başka ifadeyle yayım yanlılığına ilişkin huni grafiğinde çalışmaların asimetrik dağıldığı gözlemlenmektedir. Çalışmaların asimetrik dağglması yayım yanlılı̆̆ olduğunun göstergesi olabilir, fakat alanyazında huni grafiğindeki asimetrinin birçok sebebi olabileceği, yayım yanlılı̆̆ının ise bu sebeplerden yalnızca biri olduğu vurgulanmaktadır. $\mathrm{Bu}$ sebeple huni grafiğinin şekli yanıltıcı olabilir ve grafiğin dikkatli bir şekilde yorumlanması önemle tavsiye edilmektedir (Lau, Ioannidis, Terrin, Schmid ve Olkin, 2006; Sterne ve Harbord, 2004; Terrin, Schmid ve Lau, 2005 akt. Üstün ve Eryılmaz, 2014). Bu sebeple araştırmanın yayım yanlılığının daha detaylı ortaya konabilmesi amacıyla Klasik Güvenli N yöntemi ile Egger'in Doğrusal Regresyon Testi de kullanılmıştır. Tablo 3'te meta-analizin gücünü belirleyebilmek amacıyla yapılan Klasik Güvenli N yöntemi analiz sonuçları verilmiştir. 


\begin{tabular}{lc}
\hline Yanlılık Durumu & Değer \\
\hline$Z$-değeri & -48.88 \\
$p$-değeri & .00 \\
Alfa değeri & .05 \\
$Z$-değeri (Alfa değeri için) & 1.95 \\
$N$ & 29 \\
$p>$ alpha sonucunu elde etmek için gereken & 8009 \\
çalışmaların sayısı &
\end{tabular}

Klasik Güvenli N analizinde, çalışmanın güçlü ve güvenilir olduğu $p$ değerinin alfa değerinden küçük olması durumunda anlaşılır. Bu çalışma için yapılan analizlere göre, metaanaliz çalışmasının sonucunu istatistiksel olarak geçersiz hale getirmek için 8009 farklı çalışmanın daha meta-analize eklenmesine ihtiyaç vardır $(p<.05)$. Elde edilen bu değer, matematik kaygısı ve matematik başarısı arasındaki ilişkiye yönelik yapılan çalışmaların meta-analizinin güçlü ve yayım yanlılığının oldukça düşük olduğunu göstermektedir.

Yayım yanlılı̆̆ının belirlenmesi için başvurulan yöntemlerden bir diğeri ise "Egger'in Regresyon Testidir". Bu test huni grafiğine ilişkin asimetriyi " $p$ ” değerini kullanarak ortaya koymaktadır (Egger, Smith, Schneider ve Minder, 1997). Yapılan test sonucunda $p$ değeri .43 olarak hesaplanmıştır. $\mathrm{Bu}$ sonuç, çalışmada yayım yanlılığının olmadığını göstermektedir ( $p>.05)$.

\section{Bulgular}

\section{Ortalama Etki Büyüklüğüne İlişkin Bulgular}

Matematik kaygısı ile matematik başarısı arasındaki ilişkinin ortalama etki büyüklüğüne ilişkin sonuçlar Tablo 4'te sunulmuştur. 
Tablo 4. Rassal etki modeline göre araştırmaların etki büyüklükleri

\begin{tabular}{|c|c|c|c|c|c|c|}
\hline \multirow[t]{2}{*}{$\begin{array}{l}\text { Ortalama Etki } \\
\text { Büyüklüğü }\end{array}$} & \multirow[t]{2}{*}{ Çalışma Sayısı } & \multirow[t]{2}{*}{$\begin{array}{c}\text { Standart } \\
\text { Hata }\end{array}$} & \multirow[t]{2}{*}{$Z$} & \multirow[t]{2}{*}{$p$} & \multicolumn{2}{|c|}{$\begin{array}{c}\text { Etki Büyüklüğü } \\
\text { İçin \%095'lik } \\
\text { Güven Aralığ1 }\end{array}$} \\
\hline & & & & & Alt sinır & Üst sınır \\
\hline-.363 & 29 & .023 & -9.503 & .000 & -.430 & -.293 \\
\hline
\end{tabular}

Analiz sonuçlarına göre ortalama etki büyüklüğü değeri -.363 olarak hesaplanmıştır. Standart hata değeri de .023 olarak belirlenmiştir. \%95 güven aralığında, etki büyüklüğüne ait alt sınır -.430, üst sınır ise -.293 olarak hesaplanmıştır. İstatistiksel anlamlılık bakımından $z=4.910$ ve $p=.000$ olarak hesaplanmıştır. Ulaşılan bu değerler matematik başarısı ve matematik kaygısı arasındaki ilişkinin orta düzeyde ve negatif yönde olduğunu göstermektedir. Diğer yandan, $p$ ve $z$ değerleri göz önüne alındığında istatistiksel olarak anlamlı olduğu anlaşılmaktadır.

Mevcut çalışmada yer alan 29 çalışmaya dair etki büyüklüklerinin rassal etki modeline göre orman grafiği Şekil 2'de verilmiştir. 


\section{Meta Analysis}

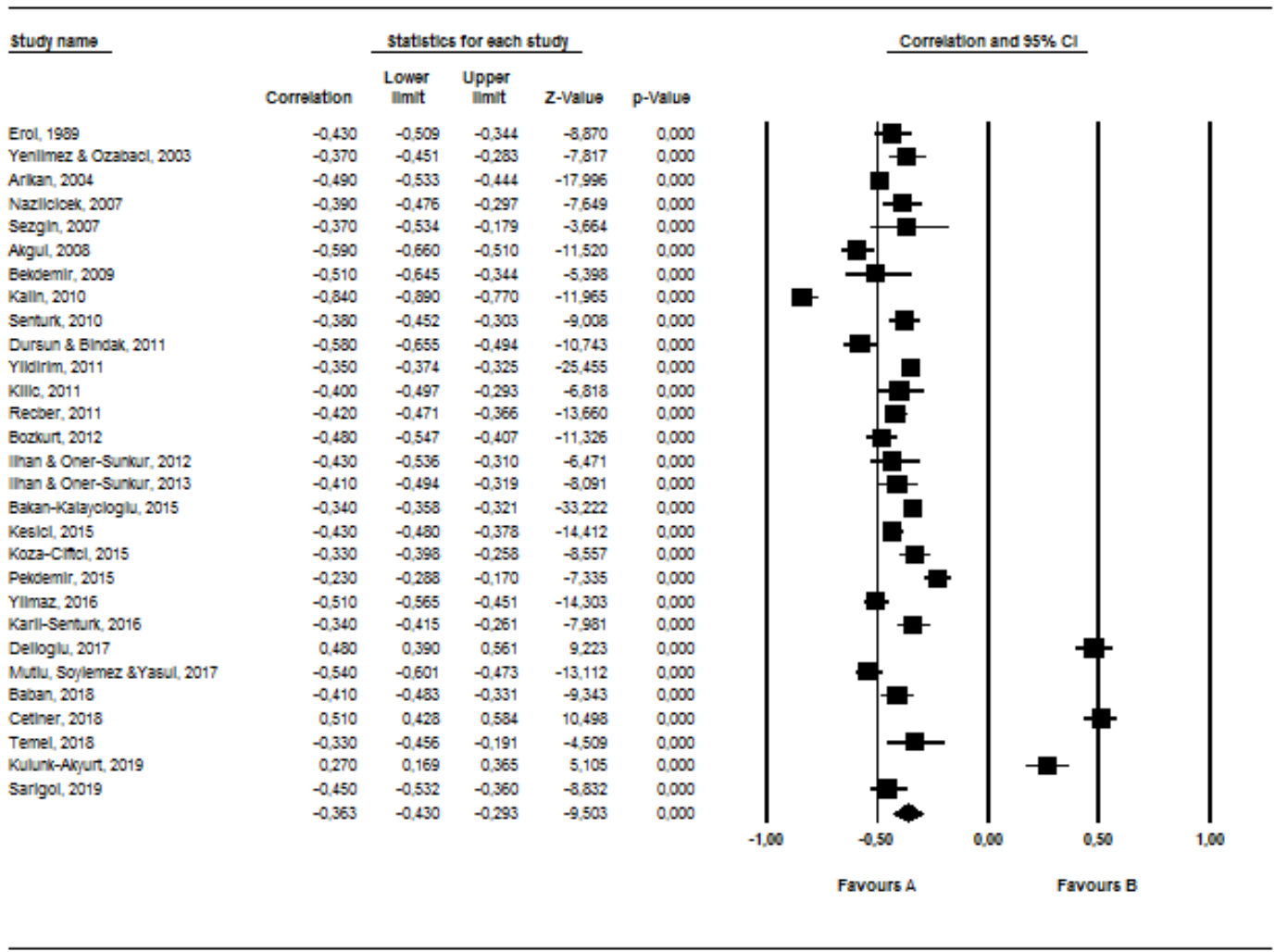

Meta Analysis

\section{Şekil 2. Meta-analizdeki çalışmaların etki büyüklüklerine ait orman grafiği}

Çalışmanın etki büyüklüğü grafikte yer alan kare şekilleri ile gösterilmektedir. Grafikteki yatay çizgiler etki büyüklüklerinin \%95 güven aralığındaki limitlerini belirtmektedir. Çalışmaların genel etki büyüklüğü ise grafiğin alt kısmında yer alan dörtgen şekil ile gösterilmektedir (Ayaz ve Söylemez, 2015). Şekil 2 incelendiğinde, çalışmaların büyük kısmında iki değişken arasında orta düzeyde negatif yönlü bir ilişkinin olduğu görülmektedir. Sadece 3 çalışmada orta düzeyde pozitif bir ilişki olduğu belirlenmiştir. Bireysel çalışmaların etki büyüklüklerine ilişkin alt ve üst güven aralıkları değerlendirildiğinde, tüm çalışmaların \%95 güven düzeyi dâhilindeki etki büyüklüğü aralıkları içerisinde olduğu görülmüştür. Toplam etki büyüklügü incelendiğinde ise güven aralığına ilişkin alt ve üst sınırların (-.430 ve -.293) Rassal Etkiler Modeli’ne göre orta düzeyde negatif etki büyüklüğü sınırları içerisinde olduğu görülebilir.

\section{Moderatör Değişkenlerin Etki Büyüklüğü Değerlerine Ait Bulgular}

Araştırma bulgularının bu bölümünde matematik kaygısı ve matematik başarısı arasındaki ilişkinin etki büyüklüğünün öğrenim kademesi değişkenine göre farklılaşıp farklılaşmadığına dair moderatör analizi bulgularına yer verilmiştir. Matematik kaygısı ve 
H. Bayırlı, M.E. Geçici ve C. Erdem / Pamukkale Üniversitesi Eğitim Fakültesi Dergisi, 53, 87-109, 202199 matematik başarısı ilişkisi etki büyüklüğünün öğrenim kademesine göre sonuçları Tablo 5 'te sunulmuştur.

Tablo 5. Öğrenim kademesi değişkenine göre çalışmaların etki büyüklüğü değerleri

\begin{tabular}{|c|c|c|c|c|c|c|}
\hline \multirow[t]{2}{*}{$\begin{array}{l}\text { Öğrenim } \\
\text { Kademesi }\end{array}$} & \multirow[t]{2}{*}{ Frekans $(n)$} & \multirow[t]{2}{*}{$\begin{array}{c}\text { Etki } \\
\text { Büyüklüğü }\end{array}$} & \multicolumn{2}{|c|}{$\begin{array}{l}\text { Etki Büyüklüğü İçin } \\
\text { \%95’lik Güven Aralığ }\end{array}$} & \multirow[t]{2}{*}{$Q_{b}$} & \multirow[t]{2}{*}{$p$} \\
\hline & & & Alt sinır & Üst sinır & & \\
\hline Ortaokul & 18 & -.384 & -.500 & -.254 & & \\
\hline Lise & 8 & -.343 & -.374 & -.310 & & \\
\hline \multicolumn{7}{|l|}{ Gruplar arası } \\
\hline toplam & 26 & -.345 & -.376 & -.313 & .388 & .534 \\
\hline
\end{tabular}

Genel etki büyüklüğünün hesaplanması için işe koşulan 29 çalışmanın 2'si ilkokul 1’i ise üniversite düzeyindedir. Etki büyüklüğünün öğrenim kademesine göre değişip değişmediğinin bulunması için yapılan moderatör analizinde ilkokul ve üniversite kademesindeki araştırmayı yürüten 3 çalışma, sayı yeterli görülmediği için analize dâhil edilmemiştir. Matematik kaygısı ile matematik başarısı arasındaki ilişkiyi ele alan bireysel araştırmaların 8'i lise kademesinde, $18^{\prime} i$ ise ortaokul kademesinde yürütülmüştür. Etki büyüklükleri öğrenim kademesine göre incelendiğinde, ortaokul düzeyinde yapılan çalışmalara ilişkin olarak matematik kaygısı ile matematik başarısı arasında orta düzeyde negatif etki büyüklügüüne ( $r=-.384)$ ulaşılmıştır ve anlamlı bir ilişkinin olduğu saptanmıştır $(p<.05)$. Lise düzeyindeki çalışmalara ilişkin olarak ise orta düzeyde negatif etki büyüklüğüne sahip ( $r=-.343)$ anlamlı bir ilişki olduğu görülmüştür $(p<.05)$.

Çalışmada ortaokul ve lise öğrenim kademelerine göre oluşturulan gruplar arasındaki fark incelendiğinde istatistiki açıdan anlamlı bir farklılığın bulunmadı̆̆ ortaya çıkmıştır $(p>.05)$. Fakat ortaokul öğrencilerinin matematik kaygısı ve matematik başarısı arasındaki ilişkinin daha yüksek olmasından dolayı, iki değişken arasındaki negatif ilişkinin ortaokul öğrencilerini lise öğrencilerine göre daha fazla etkilediği söylenebilir.

Çalışmanın bir diğer moderatör değişkeni bireysel çalışmaların yayın türüdür. Tablo 6'da matematik kaygısı ve matematik başarısı ilişkisi etki büyüklügünün yayın türüne göre sonuçları verilmiştir.

Tablo 6. Yayın türü değişkenine göre çalışmaların etki büyüklüğü değerleri 


\begin{tabular}{|c|c|c|c|c|c|c|}
\hline \multirow[t]{2}{*}{ Yayın Türü } & \multirow[t]{2}{*}{ Frekans $(n)$} & \multirow[t]{2}{*}{$\begin{array}{c}\text { Etki } \\
\text { Büyüklüğü }\end{array}$} & \multicolumn{2}{|c|}{$\begin{array}{l}\text { Etki Büyüklüğü İçin } \\
\text { \%95’lik Güven Aralığ1 }\end{array}$} & \multirow[t]{2}{*}{$Q_{b}$} & \multirow[t]{2}{*}{$p$} \\
\hline & & & Alt sinır & Üst sinır & & \\
\hline Tez & 20 & -.334 & -.452 & -.205 & & \\
\hline Makale & 9 & -.417 & -.463 & -.369 & & \\
\hline \multicolumn{7}{|l|}{ Gruplar arası } \\
\hline toplam & 29 & -.406 & -.449 & -.361 & 1.576 & .209 \\
\hline
\end{tabular}

Genel etki büyüklüğünün hesaplanabilmesi için çalışmaya dâhil edilen 29 çalışmanın 20'si tez, 9'su ise makale çalışmalarıdır. Etki büyüklükleri yayın türü değişkenine göre incelendiğinde, tezler için matematik kaygısı ile matematik başarısı arasında orta düzeyde negatif etki büyüklügüne ( $r=-.334)$ sahip ve anlamlı bir ilişkinin olduğu saptanmıştır $(p<.05)$. Benzer şekilde makale olarak yayımlanan çalışmalar için ise orta düzeyde negatif etki büyüklügüne sahip ( $r=-.417)$ anlamlı bir ilişki olduğu görülmüştür $(p<.05)$. Çalışmada tez ve makale yayın türüne göre oluşturulan gruplar arasındaki fark incelendiğinde ise istatistiksel olarak anlamlı bir farklılık olmadığı saptanmıştır ( $p>.05)$.

\section{Tartışma ve Sonuç}

$\mathrm{Bu}$ çalışma, matematik başarısını önemli düzeyde etkileyen duyuşsal faktörlerden biri olan matematik kaygısı (McLeod, 1992) ve matematik başarısı arasındaki ilişkiyi araştıran bireysel çalışmaları sentezleyerek istatistiksel olarak anlamlı sonuçlara ulaşmayı hedeflemiştir. Bunun yanı sıra matematik kaygısı ve matematik başarısı arasındaki etki büyüklüğünün öğrenim kademesi ve yayın türüne göre farklılaşıp farklılaşmadığı saptanmaya çalışılmıştır. Bu çalışmada sadece Türkiye'de yapılan çalışmalara odaklanılması çalışmanın sınırlılığı olarak gösterilebilir. Bunun yanı sıra çalışma meta-analiz yönteminin genel sınırlılıkları içerisinde yapılmıştır.

Bu meta-analiz çalışmasına 29 bireysel çalışma dâhil edilmiştir. Bu 29 bireysel çalışmada toplamda 25.704 kişiye erişilmiştir. Çalışmada heterojenlik testi sonucuna göre etki büyüklükleri dağılımının heterojen bir şekilde dağıldığı saptandığı için $(Q=956.781$; $\left.p=.00 ; I^{2}=\% 97.074\right)$ genel etki büyüklüğünün hesaplanması amacıyla Rassal Etkiler Modeli tercih edilmiştir. 
H. Bayırlı, M.E. Geçici ve C. Erdem / Pamukkale Üniversitesi Eğitim Fakültesi Dergisi, 53, 87-109, 2021101

Tercih edilen bu modele dayalı olarak gerçekleştirilen meta-analiz sonucuna göre, matematik kaygısı ve matematik başarısı arasında istatistiki olarak anlamlı, orta düzeyde negatif bir etki büyüklügüne ( $r=-.363)$ ulaş1lmıştır. Bu etki büyüklügüünün \%95'lik güven aralığının alt sınırı -.430 olarak üst sınırı ise -.293 olarak saptanmıştır. Yapılan meta-analiz sonuçlarına göre elde edilen ters yönlü etki matematik kaygısı arttıkça matematik başarısının düştüğü şeklinde anlaşılabilir. Aynı şekilde matematik başarısı azaldıkça matematik kaygısının arttığı yorumu yapılabilir. Meta-analiz sonucu elde edilen etki büyüklügü değeri ( $r=-.363$ ) alanyazında bu konuda yapılan meta-analiz çalışmalarının sonuçlarıyla uyumluluk gösterdiği tespit edilmiştir. Bu çalışmalardan birinde Ma (1999), 26 çalışmaya ait 37 etki büyüklüğünün $(n=18279)$ düşük düzeyde negatif $(r=-.27)$ bir ilişki olduğu sonucuna ulaşmıştır. Yurt dışında yürütülen bir diğer meta-analiz çalışmasında Zhang ve diğerleri (2019), 2000-2018 arası yürütülmüş 49 çalışmadan 84 etki büyüklügünü kullanarak matematik kaygısı ile matematik performansı arasında, bu çalışmanın sonucuyla neredeyse aynı olan negatif yönde bir ilişki $(r=-.32)$ olduğunu saptamışlardır. Namkung ve diğerleri (2019) ise benzer şekilde, 131 bireysel çalışmayı dâhil ettikleri çalışmalarında matematik kaygısı ile matematik performansı arasında negatif yönde bir ilişki ( $r=-.34)$ olduğu sonucuna ulaşmışlardır.

Türkiye'de matematik kaygısı ve matematik başarısı arasındaki ilişki üzerine yapılmış sadece bir meta-analiz çalışması bulunmaktadır. Şad ve diğerleri (2016), Türkiye örnekleminde gerçekleştirdikleri meta-analiz çalışmalarında 2005-2014 yılları arasında, ilkokuldan üniversite kademesine kadar yapılan 11 araştırmayı incelemişlerdir. Çalışmaya dâhil edilen 11 çalışmada toplamda 8327 kişiye ulaşılmıştır. Çalışma sonucunda matematik kaygısı ile matematik başarısı arasında mevcut çalışmaya göre daha yüksek, negatif yönde ve orta düzeyde $(r=-.44)$ bir ilişki olduğunu saptamışlardır. Bu çalışmada, Şad ve diğerlerinin (2016) incelediği 11 bireysel çalışmaya ek olarak 1989-2004 yılları arasında yürütülmüş üç çalışma (Arıkan, 2004; Erol, 2004; Yenilmez ve Özabacı, 2003) ve 20052014 yılları arasında yürütülmüş iki çalışma (İlhan ve Sünkür 2013; Kalın 2010) daha eklemiştir. Bunun yanı sıra mevcut çalışmaya 2014-2019 yılları arasında yürütülmüş 13 çalışma da eklenerek toplamda 29 çalışma etki büyüklükleri hesaplanmak üzere metaanalize dâhil edilmiştir. Bu çalışmanın, Şad ve diğerlerinin (2016) Türkiye örnekleminde yaptığı çalışmayı büyük ölçüde genişlettiği ve doğruladığı söylenebilir.

Öğrenim kademesi değişkenine göre ortaokul ve lise kademelerinde yürütülen çalışmalar için yapılan moderatör analizi sonuçlarına göre ortaokul $(r=-.384, p<.05)$ ve lise 
102 H. Bayırlı, M.E. Geçici ve C. Erdem / Pamukkale Üniversitesi Eğitim Fakültesi Dergisi, 53, 87-109, 2021

$(r=-.343, p<.05)$ kademelerinde matematik kaygısı ve matematik başarı arasındaki ilişkinin istatistiksel olarak anlamlı orta düzeyde negatif bir ilişki olduğu görülmüştür. Ortaokul kademesi için elde edilen negatif ve orta düzeydeki ilişkinin alanyazındaki ortaokul kademesinde yürütülen çalışmalarla benzer olduğu görülmüştür (Baban, 2018; İlhan ve Öner-Sünkür, 2013; Luo, Wang ve Luo, 2009; Kılıç, 2011; Şentürk, 2010; Yaratan ve Kasapoğlu, 2012). Lise kademesi için ulaşılan negatif ve orta düzeyli ilişkinin de literatürde lise kademesinde yürütülen çalışmalarla benzer olduğu görülmüştür (Bakan-Kalaycıoğlu, 2015; Karl1-Şentürk, 2016; Y1ldırım, 2011).

Araştırmada öğrenim kademelerine göre oluşan gruplar arası etki büyüklükleri incelendiğinde istatistiksel olarak anlamlı bir farklılık olmadığı $\left(Q_{b}=.388, p=.534\right)$, fakat ortaokul öğrencilerinin lise öğrencilerine kıyasla matematik kaygısının matematik başarısını daha fazla etkilediği tespit edilmiştir. Şad ve diğerlerinin (2016) yaptığı çalışmada, moderatör analizi sonucunda lise ve ortaokul kademelerinde anlamlı bir farklılık olduğu ve ortaokul öğrencilerinin lise öğrencilerine göre matematik kaygılarının matematik başarısını daha fazla etkilediği görülmüştür. Araştırmada son olarak, yayın türüne göre oluşturulan gruplar arasındaki fark incelenmiş istatistiksel olarak anlamlı bir farklılık olmadığı sonucuna varılmıştır $\left(Q_{b}=1.576, p=.209\right)$. Ancak makalelerdeki ( $\left.r=-.417\right)$ kaygı ve başarı arasındaki ilişkinin tezlerdekine ( $r=-.334)$ göre daha yüksek bir ilişkiye sahip oluğu söylenebilir.

\section{Öneriler}

Matematik kaygısı üzerine çalışma yapacak araştırmacılara ve bunun yanı sıra öğretmenlere birtakım önerilerde bulunulmuştur:

- Söz konusu bu negatif yönlü ilişkinin altında yatan sebepler detaylı bir şekilde araştırılabilir ve bu konuda çözüm önerileri geliştirilebilir.

- Matematik kaygısı ile matematik başarısı arasındaki ilişkiye odaklanan bu çalışma için sadece Türkiye'de yapılan araştırmalar dikkate alınmıştır. Bu alanda araştırma yapacak olan araştırmacılara yurt dışında yapılan çalışmaları da dâhil etmesi önerilebilir.

- Bunun yanında matematik kaygısının başka değişkenlerle ilişkisi üzerine de metaanaliz çalışmaları yapılabilir.

- Çalışmanın bulgularından hareketle öğretmenlerin de öğrencilerin başarılı olması için onların kaygılarını azaltıcı ders planı yapmaları ve öğrencilere zaman zaman bir rehber olmaları önerilebilir. 
H. Bayırl1, M.E. Geçici ve C. Erdem / Pamukkale Üniversitesi Eğitim Fakültesi Dergisi, 53, 87-109, 2021103

Etik Kurul İzin Bilgisi: Bu çalışma bir meta-analiz çalışmasıdır. Herhangi bir anket veya ölçek kullanılmadığı için etik kurul iznine gerek duyulmamıştır.

Yazar Çıkar Çatışması Bilgisi: Yazarlar çıkar çatışması olmadığını beyan etmektedir.

Yazar Katkısı: Yazarlar çalışmaya eşit oranda katkı sağlamıştır.

\section{Kaynakça}

*Akgül, S. (2008). İlköğretim ikinci kademe 7. ve 8. sınıf ögrrencilerinin matematik kaygıları ile algıladıkları ögretmen sosyal desteğinin cinsiyete göre matematik başarılarını yordama gücü (Yayımlanmamış yüksek lisans tezi). Yıldız Teknik Üniversitesi, Sosyal Bilimler Enstitüsü, İstanbul.

Ashcraft, M. H. (2002). Math anxiety: Personal, educational, and cognitive consequences. Directions in Psychological Science, 11(5), 181-185.

*Arıkan, G. (2004). Öğrencilerin matematik kaygı düzeyleri ile matematik başarı düzeyleri arasındaki ilişki -ilköğretim II. kademe- (Yayımlanmamış yüksek lisans tezi). Gazi Üniversitesi, Eğitim Bilimleri Enstitüsü, Ankara.

Ayaz, M. F., \& Söylemez, M. (2015). The effect of the project-based learning approach on the academic achievements of the students in science classes in Turkey: A metaanalysis study. Education and Science, 40(178), 255-283.

Aydın, M. ve Keskin, İ. (2017). 8. sınıf öğrencilerinin matematik kaygı düzeylerinin bazı değişkenler açısından incelenmesi. Kastamonu Ĕ̆itim Dergisi, 25(5), 1801-1818.

*Baban, A. (2018). Ortaokul ögrencilerinde matematik kaygısı ve algılanan ögretmen tutumu (Yayımlanmamış yükssek lisans tezi). Nişantaşı Üniversitesi, Sosyal Bilimler Enstitüsü, İstanbul.

*Bakan-Kalaycioğlu, D. (2015). The Influence of socioeconomic status, self-efficacy, and anxiety on mathematics achievement in England, Greece, Hong Kong, the Netherlands, Turkey, and the USA. Educational Sciences: Theory and Practice, 15(5), 1391-1401.

Bakioğlu, A. ve Özcan, Ş. (2016). Meta-analiz. Ankara: Nobel.

Baloğlu, M., \& Koçak, R. (2006). A multivariate investigation of the differences in mathematics anxiety. Personality and Individual Differences, 40(7), 1325-1335. 
104 H. Bayırlı, M.E. Geçici ve C. Erdem / Pamukkale Üniversitesi Eğitim Fakültesi Dergisi, 53, 87-109, 2021

*Bekdemir, M. (2009). Meslek yüksekokulu öğrencilerinin matematik kaygı düzeylerinin ve başarılarının değerlendirilmesi. Erzincan Üniversitesi Fen Bilimleri Enstitüsü Dergisi, 2(2), 169-189.

Borenstein, M. (2009). Effect size for continuous data. H. Cooper, L. V. Hedges ve J. C. Valentine (Eds.), The handbook of research synthesis and meta-analysis (2. Bask1) içinde. New York: Russell Sage Foundation.

*Bozkurt, S. (2012). Illköğretim ikinci kademe öğrencilerinde sınav kaygısı, matematik kaygısı, genel başarı ve matematik başarısı arasındaki ilişsilerin incelenmesi (Yayımlanmamış yüksek lisans tezi). İstanbul Üniversitesi, Sosyal Bilimler Enstitüsü, İstanbul.

Cooper, H., Hedges, L. V., \& Valentine, J. C. (2009). The handbook of research synthesis and metaanalysis (2nd edition). New York: Russell Sage Publication.

*Çetiner, İ. (2018). Sekizinci sınıf öğrencilerinin matematik kaygılarının temel ĕgitimden orta eğitime geçiş sınavındaki matematik başarılarına etkisi (Yayımlanmamış yüksek lisans tezi). Çanakkale Onsekiz Mart Üniversitesi, Eğitim Bilimleri Enstitüsü, Çanakkale.

Dede, Y. (2016). Matematik eğitimine özgü değer kategorileri ve uygulamaları. E. Bingölbali, S. Arslan ve İ. Ö. Zembat (Ed.), Matematik eğitiminde teoriler (ss. 785802) içinde. Ankara: Pegem A.

*Delioğlu, H. N. (2017). Sekizinci sınıf öğrencilerinin matematik başarısı ile sınav ve matematik kaygısı, matematiğe yönelik özyeterlik algısı arasındaki ilişki (Yayımlanmamış yüksek lisans tezi). Adnan Menderes Üniversitesi, Sosyal Bilimler Enstitüsü, Aydın.

Dinçer, S. (2014). Eğitim bilimlerinde uygulamalı meta-analiz. Ankara: Pegem Akademi.

Durlak, J. A., \& Lipsey, M. W. (1991). A practitioner's guide to meta-analysis. American Journal of Community Psychology, 19(3), 291-332.

*Dursun, Ş. ve Bindak, R. (2011). İlköğretim II. kademe öğrencilerinin matematik kaygılarının incelenmesi. Cumhuriyet Üniversitesi Edebiyat Fakültesi Sosyal Bilimler Dergisi, 35(1), 18-21.

Egger, M., Smith, G. D., Schneider, M., \& Minder, C. (1997). Bias in meta-analysis detected by a simple, graphical test. British Medical Journal, 315(7109), 629-634. 
H. Bayırlı, M.E. Geçici ve C. Erdem / Pamukkale Üniversitesi Eğitim Fakültesi Dergisi, 53, 87-109, 2021105

*Erol, E. (1989). Prevalence and correlates of math anxiety in Turkish high school students (Unpublished Master Thesis). Boğaziçi University, İstanbul.

Fennema, E., \& Sherman, J. A. (1976). Fennema-Sherman mathematics attitudes scales: Instruments designed to measure attitudes toward the learning of mathematics by females and males. Journal for Research in Mathematics Education, 7(5), 324-326.

Glass, G. V. (1976). Primary, secondary, and meta-analysis of research. Educational researcher, 5(10), 3-8.

Gürbüz, R., \& Yıldırım, K. (2016). An investigation of mathematics anxiety of primary school teachers. Turkish Journal of Computer and Mathematics Education, 7(3), 536-552.

Haciömeroğlu, G. (2019). İlkokul öğrencilerinin teknoloji destekli matematik öğrenmeye yönelik tutum ve kaygı düzeylerinin incelenmesi. Journal of Computer and Education Research, 7(14), 356-382. DOI:10.18009/jcer.581625

Hannula M. S. (2014). Affect in mathematics education. S. Lerman (Ed.), Encyclopedia of mathematics education (pp.23-27) içinde. Dordrecht: Springer.

Hembree, R. (1990). The nature, effects and relief of mathematics anxiety. Journal for Research in Mathematics Education, 26(1), 33-46.

Hoffman, B. (2010). "I think I can, but I'm afraid to try": The role of self-efficacy beliefs and mathematics anxiety in mathematics problem-solving efficiency. Learning and individual differences, 20(3), 276-283. https://doi.org/10.1016/j.lindif.2010.02.001

*İlhan, M. ve Öner-Sünkür, M. (2012). Matematik kaygısı ile olumlu ve olumsuz mükemmelliyetçiliğin matematik başarısını yordama gücü. Mersin Üniversitesi Ĕ̈itim Fakültesi Dergisi, 8(1), 178-188.

*İlhan, M. ve Öner-Sünkür, M. (2013). Matematik kaygısının matematik başarısını yordama gücünün cinsiyet ve sınıf değişkeni açısından incelenmesi. Gaziantep University Journal of Sciences, 12(3), 427-441.

Kaba, Y., \& Şengül, S. (2018). The relationship between middle school students' mathematics anxiety and their mathematical understanding. Pegem Eğitim ve Ö̆retim Dergisi, 8(3), 599-622. http://dx.doi.org/10.14527/pegegog.2018.023 
106 H. Bayırlı, M.E. Geçici ve C. Erdem / Pamukkale Üniversitesi Eğitim Fakültesi Dergisi, 53, 87-109, 2021

*Kalın, G. (2010). Ilköğretim öğrencilerinin matematik tutumları, özyeterlikleri, kaygıları ve dersteki başarılarının incelenmesi (Yayımlanmamış yüksek lisans tezi). Başkent Üniversitesi, Eğitim Bilimleri Enstitüsü, Ankara.

*Karlı-Şentürk, C. (2016). Lise öğrencilerinin matematik kaygılarının yordanması (Yayımlanmamış yüksek lisans tezi). Ahi Evran Üniversitesi, Sosyal Bilimler Enstitüsü, Kırşehir.

*Kesici, A. (2015). Ortaokul öğrencilerinin matematiğe yönelik duyuşsal özellikleri ile temel ĕgitimden ortaögretime geçiş (TEOG) sinavları öncesi yaşadıkları stresin matematik başarısına etkisi (Doktora tezi). Dicle Üniversitesi, Eğitim Bilimleri Enstitüsü, Diyarbakır.

*Kılıç, A. S. (2011). İlköğretim ikinci kademe öğrencilerinin genel başarıları, matematik başarıları, matematik dersine yönelik tutumları, güdülenmeleri ve matematik kaygıları arasındaki ilişki (Yayımlanmamış yüksek lisans tezi). Gazi Üniversitesi, Eğitim Bilimleri Enstitüsü, Ankara.

*Koza-Çiftçi, Ş. (2015). Effects of secondary school students' perceptions of mathematics education quality on mathematics anxiety and achievement. Educational Sciences: Theory and Practice, 15(6), 1487-1501.

*Külünk-Akyurt, G. (2019). İlkokul 4. sınıf öğrencilerinin matematik motivasyonu, kaygısı ve başarısı arasındaki ilişkinin incelenmesi (Yayımlanmamış yüksek lisans tezi). Ordu Üniversitesi, Sosyal Bilimler Enstitüsü, Ordu.

Lee, O., \& Brophy, J. (1996). Motivational patterns observed in sixth-grade science classrooms. Journal of Research in Science Teaching: The Official Journal of the National Association for Research in Science Teaching, 33(3), 303-318.

Lim, S. Y., \& Chapman, E. (2015). Identifying affective domains that correlate and predict mathematics performance in high-performing students in Singapore. Educational Psychology, 35(6), 747-764.

Luo, X., Wang, F., \& Luo, Z. (2009). Investigation and analysis of mathematics anxiety in middle school students. Journal of mathematics Education, 2(2), 12-19.

Ma, X. (1999). A meta-analysis of the relationship between anxiety toward mathematics and achievement in mathematics. Journal for Research in Mathematics Education, 30(5), 520-540. 
H. Bayırl1, M.E. Geçici ve C. Erdem / Pamukkale Üniversitesi Eğitim Fakültesi Dergisi, 53, 87-109, 2021107

McLeod, D. B. (1992). Research on affect in mathematics education: A reconceptualization. In D. A. Grouws (Ed.), Handbook of research on mathematics teaching and learning (pp. 575-596). New York: Macmillan.

*Mutlu, Y., Söylemez, İ. ve Yasul, A. F. (2017). İlkokul öğrencilerinin matematik kaygıs1 ile matematik başarıları arasındaki ilişkinin incelenmesi. Journal of Human Sciences, 14(4), 4425-4434.

Mutodi, P., \& Ngirande, H. (2014). Exploring mathematics anxiety: Mathematics students' experiences. Mediterranean Journal of Social Sciences, 5(1), 283-294. Doi:10.5901/mjss.2014.v5n1p283

Namkung, J. M., Peng, P., \& Lin, X. (2019). The relation between mathematics anxiety and mathematics performance among school-aged students: A meta-analysis. Review of Educational Research, 89(3), 459-496.

*Nazlıçiçek, N. (2007). Onuncu sınıf öğrencilerinin matematik başarılarını açıklayıcı bir model çalışması (Yayımlanmamış doktora tezi). Yıldız Teknik Üniversitesi, Sosyal Bilimler Enstitüsü, İstanbul.

Pajares, F., \& Graham, L. (1999). Self-efficacy, motivation constructs, and mathematics performance of entering middle school students. Contemporary Educational Psychology, 24(2), 124-139.

Pajares, F., \& Miller, M. D. (1994). Role of self-efficacy and self-concept beliefs in mathematical problem solving: A path analysis. Journal of Educational Psychology, 86(2), 193-203.

*Pekdemir, Ü. (2015). Dokuz ve onuncu sınıf ögrencilerinin matematik başarlları ile matematik kaygıları, benlik saygıları, akademik öz-yeterlik inançları ve otomatik düşünceleri arasındaki ilişkiler (Yayımlanmamış yüksek lisans tezi). Karadeniz Teknik Üniversitesi, Eğitim Bilimleri Enstitüsü, Trabzon.

Peker, M., \& Ertekin, E. (2011). The relationship between mathematics teaching anxiety and mathematics anxiety. The New Educational Review, 23(1), 213-226.

Peker, M. ve Şentürk, B. (2012). İlköğretim 5. sınıf öğrencilerinin matematik kaygılarının bazı değişkenler açısından incelenmesi. Dumlupınar Üniversitesi Sosyal Bilimler Dergisi, 34, 21-32. 
108 H. Bayırlı, M.E. Geçici ve C. Erdem / Pamukkale Üniversitesi Eğitim Fakültesi Dergisi, 53, 87-109, 2021

Ramirez, G., Gunderson, E. A., Levine, S. C., \& Beilock, S. L. (2013). Math anxiety, working memory, and math achievement in early elementary school. Journal of Cognition and Development, 14(2), 187-202. DOI: 10.1080/15248372.2012.664593

*Reçber, S.. (2011). An investigation of the relationship among the seventh grade students' mathematics self efficacy, mathematics anxiety, attitudes towards mathematics and mathematics achievement regarding gender and school type (Unpublished master thesis). Middle East Technical University, Ankara.

Richardson, F. C., \& Suinn, R.M. (1972). The mathematics anxiety rating scale: Psychometric data. Journal of Counseling Psychology, 19(6), 551-554.

Sarı, M. H. ve Ekici, G. (2018). İlkokul 4. sınıf öğrencilerinin matematik başarıları ile aritmetik performanslarını etkileyen duyuşsal değişkenlerin belirlenmesi. OPUS Uluslararası Toplum Araştırmaları Dergisi, 8(15), 1562-1594.

*Sarıgöl, S. (2019). The role of parental math anxiety in students' math anxiety and performance (Unpublished master thesis). Boğaziçi University, İstanbul.

Schunk, D. H. (1991). Self-efficacy and academic motivation. Educational Psychologist, 26, 207-231.

Schunk, D. H. (2005). Self-regulated learning: The educational legacy of Paul R. Pintrich. Educational Psychologist, 40(2), 85-94.

*Sezgin, M. (2007). Öğrencilerin matematik başarılarına etki eden faktörler (Yayımlanmamış yüksek lisans tezi). Beykent Üniversitesi, Sosyal Bilimler Enstitüsü, İstanbul.

Sırmacı, N. (2007). Üniversite öğrencilerinin matematiğe karşı kaygı ve tutumlarının incelenmesi: Erzurum örneklemi. Eğitim ve Bilim, 32(145), 53-70.

Şad, S. N., Kış, A., Demir, M., \& Özer, N. (2016). Meta-analysis of the relationship between mathematics anxiety and mathematics achievement. Pegem Ĕ̈itim ve Öğretim Dergisi, 6(3), 371-392. http://dx.doi.org/10.14527/pegegog.2016.019.

*Şentürk, B. (2010). Illköğretim beşinci sınıf ögrencilerinin genel başarıları, matematik başarıları, matematik dersine yönelik tutumları ve matematik kaygıları arasındaki ilişsi (Yayımlanmamış yüksek lisans tezi). Afyon Kocatepe Üniversitesi, Sosyal Bilimler Enstitüsü, Afyonkarahisar. 
H. Bayırlı, M.E. Geçici ve C. Erdem / Pamukkale Üniversitesi Eğitim Fakültesi Dergisi, 53, 87-109, 2021109

*Temel, Z. (2018). 8. Sinıf ögrencilerinin matematiğe yönelik tutum ve kaygılarının üslü ifadeler konusundaki başarıyı yordama gücü (Yayımlanmamış yüksek lisans tezi). Necmettin Erbakan Üniversitesi, Eğitim Bilimleri Enstitüsü, Konya.

Toptaş, V. ve Gözel, E. (2018). Türkiye'de matematik kaygısı ile ilgili yapılan lisansüstü tezlerin içerik analizi. Eğitim Kuram ve Uygulama Araştırmaları Dergisi, 4(3), 136146.

Üstün, U., \& Eryılmaz, A. (2014). A research methodology to conduct effective research syntheses: Meta-analysis. Education and Science, 39(174), 1-32.

Yaratan, H., \& Kasapoğlu, L. (2012). Eighth grade students' attitude, anxiety, and achievement pertaining to mathematics lessons. Procedia-Social and Behavioral Sciences, 46, 162-171.

*Yenilmez, K. ve Özabac1, N. (2003). Yatılı öğretmen okulu öğrencilerinin matematik ile ilgili tutumları ve matematik kaygı düzeyleri arasındaki ilişki üzerine bir araştırma. Pamukkale Üniversitesi Eğitim Fakültesi Dergisi, 14, 132-146.

Yetgin, O. ve Kara, A. (2018). Ortaöğretim öğrencilerinin matematik kaygısı ve öğrenmeye ilişskin tutumlarının incelenmesi. Yaşadıkça Eğitim Dergisi, 32(2), 16-27.

*Yıldırım, S. (2011). Öz-yeterlik, içe yönelik motivasyon, kaygı ve matematik başarısı: Türkiye, Japonya ve Finlandiya'dan bulgular. Necatibey Eğitim Fakültesi Elektronik Fen ve Matematik Eğitimi Dergisi, 5(1), 277- 291.

Yıldırım, N. (2014). Meta analiz. Metin, M. (Ed.), Eğitimde bilimsel araştırma yöntemleri içinde (s. 137-159). Ankara: Pegem Akademi.

*Yılmaz, H. R. (2015). İlköğretim ikinci kademe ögrencilerinde matematik başarısı ile matematik kaygısı, sınav kaygısı ve bazı demografik değişkenlerle ilişkisinin incelenmesi (Yüksek lisans tezi). Gaziantep Üniversitesi, Eğitim Bilimleri Enstitüsü, Gaziantep.

Zhang, J., Zhao, N ., \& Kong, Q. P. (2019). The relationship between math anxiety and math performance: A meta-analytic investigation. Frontiers in Psychology, 10, 1613. doi: 10.3389/fpsyg.2019.01613

(* ile işaretlenmiş kaynaklar meta-analiz çalışmasına dâhil edilmiş olan çalışmalardır.) 


\title{
The Relationship between Mathematics Anxiety and Mathematics Achievement: A Meta-Analysis Study
}

\author{
Hakan BAYIRLI*, Mehmet Ertürk GEÇİCI'**, Cahit ERDEM ${ }^{* * *}$
}

- Received: 20.08.2020 • Accepted: 23.01.2021 • Online First: 08.04.2021

\begin{abstract}
This study aims to statistically synthesize the results of research studies examining the relationship between mathematics anxiety and mathematics achievement carried out in Turkey. To this end, the mean effect size of the relationship between the two variables was calculated in the current study using the meta-analysis method. In addition, the mean effect size was examined in terms of moderator variables such as school level and publication type. After implementing the inclusion criteria, the meta-analysis was performed with 29 independent studies. The total sample size of these studies is 25704 . The mean effect size of the relationship between the two variables is -.363, which indicates a negative and medium level relationship. The effect sizes do not differ significantly in terms of moderator variables of school level and publication type.
\end{abstract}

Keywords: Mathematics achievement, mathematics anxiety, school level, publication type

\section{Cited:}

Bayırlı, H., Geçici, M.E. \& Erdem, C. (2021). The relationship between mathematics anxiety and mathematics achievement: A meta-analysis study. Pamukkale University Journal of Education, 53, 87-109. doi: 10.9779/pauefd.783083.

\footnotetext{
* Res. Asst., Afyon Kocatepe University, Faculty of Education, Afyonkarahisar, Türkiye, hbayirli@aku.edu.tr, ORCID ID: https://orcid.org/0000-0002-8415-5418

${ }^{* *}$ Res. Asst., Afyon Kocatepe University, Faculty of Education, Afyonkarahisar, Türkiye, megecici@aku.edu.tr, ORCID ID: https://orcid.org/0000-0002-5250-1419

*** Asst. Prof. Dr., Afyon Kocatepe University, Faculty of Education, Afyonkarahisar, Türkiye, cerdem@aku.edu.tr, ORCID ID: https://orcid.org/0000-0001-6988-8122
} 


\section{Introduction}

Mathematics is an objective and logical academic discipline. On the other hand, it is widely accepted that mathematical thinking is not just reasoning based on logic, but also it is affected to a great extent by affective factors (Hannula, 2014). Like cognitive factors, affective factors affect how students use mathematics in their career planning and how they approach mathematics (Dede, 2016). In the same vein, several researchers have highlighted the significant role of affective behaviors in mathematics education (Fennema \& Sherman, 1976; Lee \& Brophy, 1996; McLeod, 1992).

Students' affective skills consist of a variety of factors, including attitude, interest, motivation, self-efficacy, self-regulation, belief, anxiety, and value (Ashcraft, 2002; Fennema \& Sherman, 1976; Hannula, 2014; McLeod, 1992; Pajares \& Graham, 1999; Pajares \& Miller, 1994; Schunk, 1991, 2005). Sar1 and Ekici (2018) examined the data of countries that had achieved high scores in international tests such as PISA and TIMMS, and concluded that affective variables were among the most significant factors affecting students' achievement. Besides, a very strong relationship between mathematics achievement and students' affective characteristics such as anxiety, attitude, and motivation is evidenced in the literature (Lim \& Chapman, 2015).

McLeod (1992) asserts that mathematics anxiety is the area that attracts the most attention among affective areas. In addition, McLeod (1992) also emphasizes that mathematics anxiety is a construct that is in relation to affections such as tension, despair, dislike, worry, and fear experienced in mathematics lessons. Similarly, Baloğlu and Koçak (2006) argue that anxiety is one of the most common problems with regard to mathematics. Peker and Ertekin (2011) also regard anxiety as one of the affective causes of failure in mathematics. Research to date has established that mathematics anxiety affects mathematics achievement negatively (Hembree, 1990; Ma, 1999; Namkung, Peng \& Lin, 2019; Peker \& Şentürk, 2012; Ramirez, Gunderson, Levine \& Beilock, 2013; Sarı \& Ekici, 2018; Şad, Kış, Demir \& Özer, 2016; Zhang, Zhao \& Kong, 2019).

Earlier studies on mathematics anxiety started with teachers' observations around the 1950s yet it could not find a place in educational research until the 1970s (Yetgin \& Kara, 2018). A considerable amount of literature has been published on mathematics anxiety since the 1970s (Ashcraft, 2002; Aydın \& Keskin, 2017; Gürbüz \& Yıldırım, 2016; Hacıömeroğlu, 2019; Hembree, 1990; Hoffman, 2010; Kaba \& Şengül, 2018; Ma, 1999; McLeod, 1992; Mutodi \& Ngirande, 2014; Peker \& Şentürk, 2012; Ramirez et al., 2013). 
Peker and Şentürk (2012) contend that mathematics anxiety prevails from the primary education level to tertiary education. Correspondingly, Sirmac1 (2007) argues that students develop negative attitudes towards mathematics in the early years of elementary education due to the anxiety caused by a failure in understanding mathematics, and maintains that this results in learning losses or delays. As well as affecting students academically, mathematics anxiety also leads to tensions in everyday operations such as calculation or counting money which require the use of mathematics (Richardson \& Suinn, 1972).

Mathematics anxiety affects students' choices of professions and future plans, as well (Hembree, 1990). Toptaş and Gözel (2018) also highlight that mathematics anxiety hinders learning mathematics substantially, leads to negative attitudes towards mathematics, and it has long been a problem. Therefore, paying regard to research studies in this issue may contribute to teaching mathematics.

A review of the literature suggests that some meta-analysis studies on mathematics anxiety have been published covering different periods of time (Hembree, 1990; Ma, 1999; Namkung et al., 2019; Şad et al., 2016; Zhang et al., 2019). The relationship between mathematics anxiety and mathematics achievement is the main focus of these studies. Hembree (1990) analyzed the results of 151 studies and identified a medium-level negative relationship $(r=-.34)$ between mathematics anxiety and mathematics achievement. Ma (1999) calculated 37 effect sizes out of 26 studies and revealed a small negative $(r=-.27)$ relationship between them.

In their meta-analysis study, Şad et al. (2016) analyzed 11 studies published between 2005-2014 in Turkey. They identified a medium-level negative $(r=-.44)$ relationship between mathematics anxiety and mathematics achievement. In the moderator analysis regarding school levels, e negative medium-level relationship was revealed both for lower secondary school $(\mathrm{r}=-.49)$ and high school $(r=-.34)$. In the comparisons regarding the effect values, they concluded that the negative relationship between mathematics achievement and mathematics anxiety affected lower secondary school students at a greater degree than high school students. In another meta-analysis study, Zhang et al. (2019) identified a negative relationship $(\mathrm{r}=-.32)$ between the variables. Namkung et al. (2019), similarly, found a negative relationship $(\mathrm{r}=-.34)$ between mathematics anxiety and performance in mathematics. The existing body of research including these meta-analysis studies on 
mathematics anxiety suggests that mathematics anxiety affects mathematics achievement negatively. The effect sizes also vary among the studies.

Several studies on the relationship between mathematics anxiety and mathematics achievement have been published in Turkey recently (Bakan-Kalaycıoğlu, 2015; Bozkurt, 2012; Dursun \& Bindak, 2011; İlhan \& Öner-Sünkür, 2012, 2013; Kesici, 2015; K1lıç, 2011; Külünk-Akyurt, 2019; Mutlu, Söylemez \& Yasul, 2017; Peker \& Şentürk, 2012; Reçber, 2011; Sarıöl, 2019; Temel, 2018). It is thought that current meta-analysis studies that comprehensively analyze the different results obtained from these studies pertaining to different samples may contribute to the literature to better understand the nature of the relationship between the two variables.

\section{Purpose of the Study}

This study aims to statistically synthesize the results of research studies examining the relationship between mathematics anxiety and mathematics achievement carried out in Turkey. With this meta-analysis study, it is thought that a comprehensive result regarding the relationship between mathematics anxiety and mathematics achievement can be reached. To this end, the research questions are as follows:

1. What is the mean effect size of the relationship between students' mathematics anxiety and mathematics achievement?

2. Do the effect sizes of the relationship between students' mathematics anxiety and mathematics achievement differ significantly in terms of school levels and publication types?

\section{Method}

\section{Research Design}

Meta-analysis involves statistically expressing a wide collection of analysis findings identified through individual studies with an aim to combine them (Glass, 1976). In the current study, the effect sizes of the findings obtained from individual studies examining the relationship between mathematics anxiety and mathematics achievement were calculated through the meta-analysis method. The meta-analysis method is a quantitative research method that forms hypotheses- differently from literature reviews- and resorts to statistical techniques and quantitative data to test the accuracy of these hypotheses (Durlak \& Lipsey, 1991). 
In meta-analysis studies, researchers code the studies that meet the inclusion criteria. In order to compare individual studies carried out by different researchers, the findings of studies in which instruments, data analyses, and inherently measurement results differ from each other should be standardized. An overall effect size is obtained following the synthesis of effect sizes of individual studies (Yıldırım, 2014).

\section{Sample and Inclusion Criteria}

In order to identify the studies to be included in the meta-analysis, the databases of the Turkish Council of Higher Education Thesis Center, Google Scholar and TR Dizin were searched. Keywords of "anxiety", "mathematics anxiety", and "achievement" and their Turkish equivalents were used in this search. After the search with the keywords in the databases, a total of 150 studies consisting of 68 articles and 87 theses were accessed. The last date of the search was 5 May 2020. The inclusion criteria in determining which study to include in the analysis are as follows:

1. It should be a correlational study regarding the relationship between mathematics anxiety and mathematics achievement,

2. The study should include sample sizes and statistical values such as $\mathrm{p}$ and 2 ,

3. The study should be published in Turkey,

4. The study should be in Turkish or English.

After the search and application of inclusion criteria, the meta-analysis was performed with 29 studies. Of these 29 studies investigating the relationship between mathematics anxiety and mathematics achievement, 20 are theses and 9 are articles. It was observed that some of the articles were produced from these. For such kind of studies, only theses were included in the meta-analysis.

\section{Coding and Characteristics of the Studies}

The studies were coded to compare the effect sizes of the studies included in the metaanalysis. The form during the coding process involved the headings below.

- Authors

- Publication type

- School level

- Sample size 
- Correlation coefficient

Two researchers coded the studies. The characteristics of the studies are presented in Table 1.

Table 1. Characteristics of studies included in the meta-analysis

\begin{tabular}{|c|c|c|c|c|}
\hline Authors & $\begin{array}{c}\text { Publication } \\
\text { Type }\end{array}$ & School Level & $\begin{array}{l}\text { Sample } \\
\text { Size }(n)\end{array}$ & $\begin{array}{c}\text { Correlation } \\
\text { Coefficient } \\
(r)\end{array}$ \\
\hline Erol, 1989 & Thesis & High school & 375 & -.43 \\
\hline Yenilmez \& Özabacı, 2003 & Article & High school & 408 & -.37 \\
\hline Arıkan, 2004 & Thesis & Lower sec. & 1130 & -.49 \\
\hline Nazlıçiçek, 2007 & Thesis & High school & 348 & -.39 \\
\hline Sezgin, 2007 & Thesis & High school & 92 & -.37 \\
\hline Akgül, 2008 & Thesis & Lower sec. & 292 & -.59 \\
\hline Bekdemir, 2009 & Article & University & 95 & -.51 \\
\hline Kalın, 2010 & Thesis & Lower sec. & 99 & -.84 \\
\hline Şentürk, 2010 & Thesis & Lower sec. & 510 & -.38 \\
\hline Dursun \& Bindak, 2011 & Article & Lower sec. & 266 & -.58 \\
\hline Y1ldırım, 2011 & Article & High school & 4855 & -.35 \\
\hline K1lıç, 2011 & Thesis & Lower sec. & 262 & -.40 \\
\hline Reçber, 2011 & Thesis & Lower sec. & 934 & -.42 \\
\hline Bozkurt, 2012 & Thesis & Lower sec. & 472 & -.48 \\
\hline İlhan \& Öner-Sünkür, 2012 & Article & Lower sec. & 201 & -.43 \\
\hline İlhan \& Öner-Sünkür, 2013 & Article & Lower sec. & 348 & -.41 \\
\hline
\end{tabular}




\begin{tabular}{|c|c|c|c|c|}
\hline Bakan-Kalaycıoğlu, 2015 & Article & High school & 8806 & -.34 \\
\hline Kesici, 2015 & Thesis & Lower sec. & 985 & -.43 \\
\hline Koza-Çiftçi, 2015 & Article & Lower sec. & 626 & -.33 \\
\hline Pekdemir, 2015 & Thesis & High school & 984 & -.23 \\
\hline Y1lmaz, 2015 & Thesis & Lower sec. & 649 & -.51 \\
\hline Karl1-Şentürk, 2016 & Thesis & High school & 511 & -.34 \\
\hline Delioğlu, 2017 & Thesis & Lower sec. & 314 & .48 \\
\hline Mutlu et al., 2017 & Article & Primary & 474 & -.54 \\
\hline Baban, 2018 & Thesis & Lower sec. & 463 & -.41 \\
\hline Çetiner, 2018 & Thesis & Lower sec. & 351 & .51 \\
\hline Temel, 2018 & Thesis & Lower sec. & 176 & -.33 \\
\hline Külünk-Akyurt, 2019 & Thesis & Primary & 343 & .27 \\
\hline Sarıgöl, 2019 & Thesis & Lower sec. & 335 & -.45 \\
\hline
\end{tabular}

As is given in Table 1, the sample of eight studies is high school students, the sample of 18 studies is lower secondary school students, the sample of two studies is primary school students and the sample of one study is university students. The total size of the sample in the current meta-analysis study is 25704 . The publication year of the studies vary between 1989 and 2019. It is observed that the number of studies on this issue has increased in recent years.

\section{Effect Size Analysis}

Comprehensive Meta-Analysis (CMA) was used in this study to perform the meta-analysis. In the meta-analysis method, a fixed effects model and a random effects model are used to interpret the mean effect size (Borenstein, 2009). The heterogeneity among the studies is checked to decide whether to use fixed effects model or random effects model (Üstün \& Ery1lmaz, 2014). The heterogeneity test results are provided in Table 2. 
Table 2. The heterogeneity test results

\begin{tabular}{cccc}
\hline Heterogeneity Value $(Q)$ & Degree of Freedom $(d f)$ & $I^{2}$ & $p$ \\
\hline 956.981 & 28 & 97.07 & .000 \\
\hline
\end{tabular}

As a result of the heterogeneity test, the effect sizes of mathematics anxiety and mathematics achievement studies were found as statistically significant. In the heterogeneity test, a $p$ value smaller than .05 means that meta-analysis has a heterogeneous structure, and the random effects model should be used in this case (Dinçer, 2014, p.47). In addition, $I^{2}$ value was calculated as $97.07 \%$, which referred to a high level of heterogeneity. A value of $75 \%$ and over $I^{2}$ value means high heterogeneity (Cooper, Hedges \& Vallentine, 2009). Therefore, the random effects model was used in the current study to calculate the effect sizes regarding the relationship between mathematics anxiety and mathematics achievement.

\section{Publication Bias}

One of the biggest concerns in meta-analysis studies is the assumption of publication bias which posits that the studies in the meta-analytic data set include published research, journals tend to reject studies that report insignificant results, and the published research generally report similar results (Bakioğlu \& Özcan, 2016; Üstün \& Ery1lmaz, 2014). To determine if there was a publication bias in the studies included in the data set, first the Funnel Plot was used and it was followed by Rosenthal's fail-safe N (FSN), and Egger's linear regression test methods. The funnel plot regarding the relationship between mathematics anxiety and mathematics achievement is provided in Figure 1. 


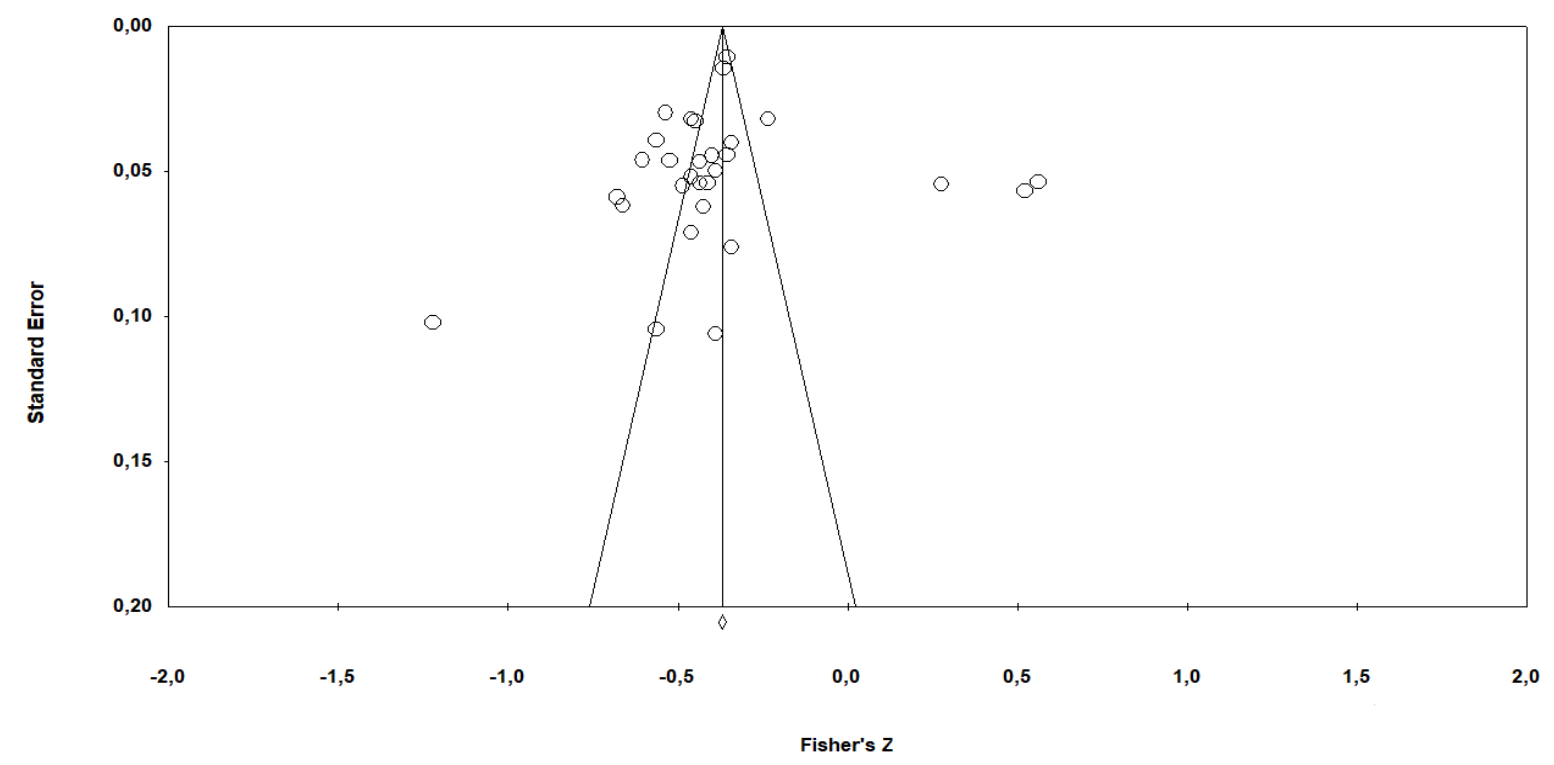

Figure 1. Funnel plot regarding the effects sizes of the studies in the data set

Figure 1 manifests that most of the studies included in the meta-analysis gathered in the middle inner areas of the funnel plot. The effect sizes of the studies are on the left of the line which represents the overall effect size. In other words, the studies are scattered asymmetrically in the funnel plot. The asymmetrical scattering of the studies may indicate publication bias yet the literature highlights that there are many reasons for asymmetrical scattering, and publication bias may just be one of these reasons. Therefore the funnel plot may be misleading and it should be interpreted meticulously (Lau, Ioannidis, Terrin, Schmid \& Olkin, 2006; Sterne \& Harbord, 2004; Terrin, Schmid \& Lau, 2005 as cited in Üstün \& Ery1lmaz, 2014). Hence, classic fail-safe N (FSN), and Egger's linear regression test methods were used to examine publication bias in more detail. Table 3 presents the results of classic FSN methods.

Table 3. Publication bias statistics of the studies

Bias Status $\quad$ Value

Z-value

$-48.88$

$p$-value

Alpha value 
In classic FSN analysis, a $p$ value that is smaller than the alpha value means that the study is robust and reliable. This analysis suggests that 8009 different studies should be added to the meta-analysis to invalidate the results of the meta-analysis statistically $(\mathrm{p}<.05)$. This value posits that the current meta-analysis of the studies on the relationship between mathematics anxiety and mathematics achievement is robust and has a very low publication bias.

Another method used in the determination of publication bias is Egger's linear regression test. This test uses $p$ value to reveal the asymmetry regarding the funnel plot (Egger, Smith, Schneider \& Minder, 1997). The test produced a $p$ value of .43. This value indicates that there is no publication bias $(\mathrm{p}>.05)$.

\section{Findings}

\section{Findings Regarding the Mean Effect Size}

Results regarding the mean effect size of the relationship between mathematics anxiety and mathematics achievement are presented in Table 4.

Table 4. Effect sizes of the studies based on random effects model

\begin{tabular}{|c|c|c|c|c|c|c|}
\hline $\begin{array}{c}\text { Mean Effect } \\
\text { Size }\end{array}$ & $\begin{array}{c}\text { Number of } \\
\text { Studies }\end{array}$ & $\begin{array}{c}\text { Standard } \\
\text { Error }\end{array}$ & $Z$ & $p$ & \multicolumn{2}{|c|}{$\begin{array}{c}\text { Confidence } \\
\text { Interval }(95 \%)\end{array}$} \\
\hline & & & & & Lower & Upper \\
\hline & & & & & Limit & Limit \\
\hline-.363 & 29 & .023 & -9.503 & .000 & -.430 & -.293 \\
\hline
\end{tabular}

The value of the mean effect size is -.363 . The standard error value is .023 . In $95 \%$ confidence interval, the lower limit of the effect size is -.430 and the upper limit is -.293. Regarding statistical significance, $z$ is $z=4.910$ and $p$ is $p=.000$. These values reveal that the relationship between mathematics achievement and mathematics anxiety is negative and medium-level. In addition, considering the $p$ and $z$ values, it is statistically significant. 
The forest plot of the effect sizes of 29 studies in the meta-analysis based on the random effects model is presented in Figure 2.

\section{Meta Analysis}

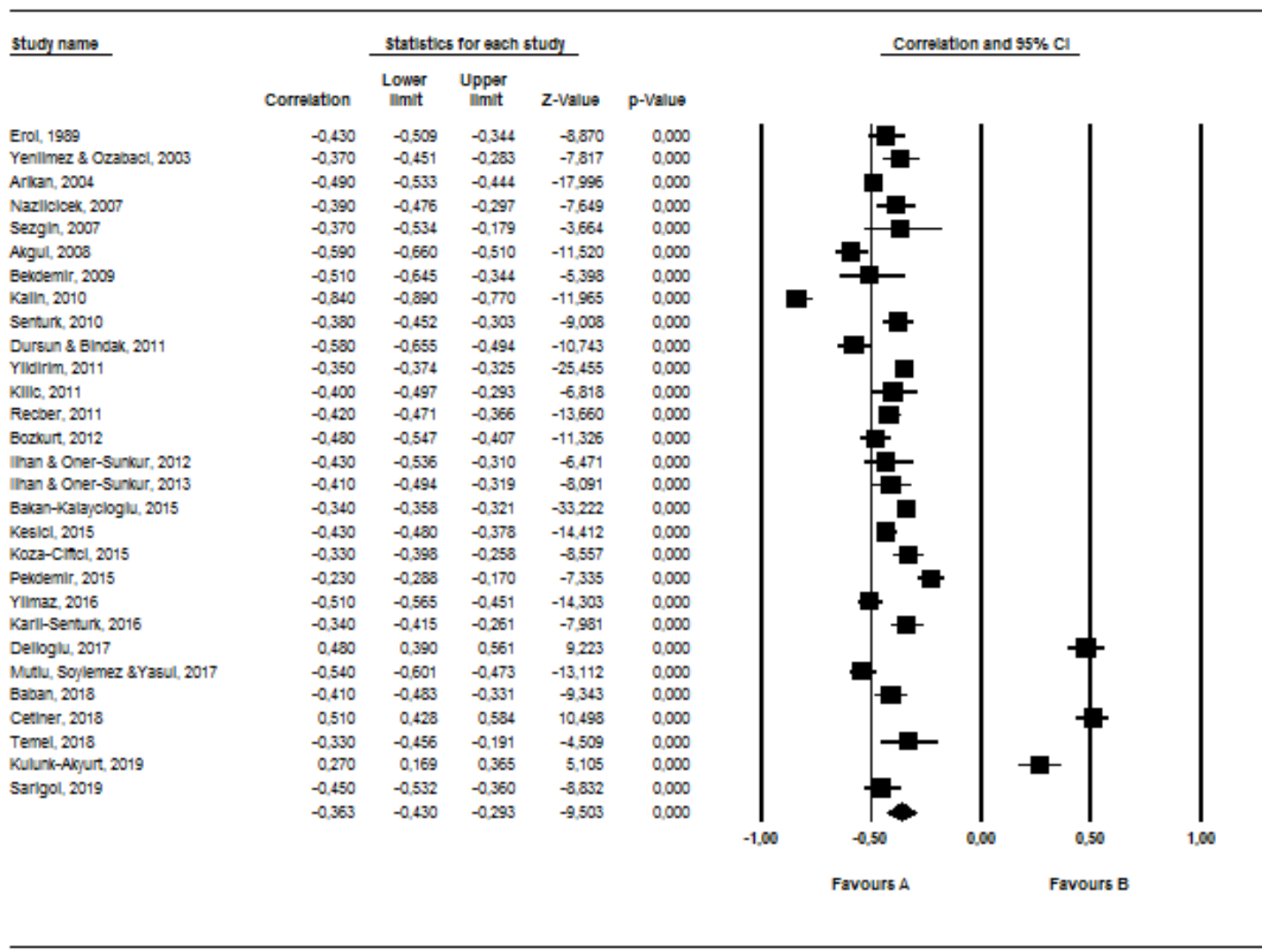

Meta Analysis

Figure 2. The forest plot regarding the effect sizes of the studies in the meta-analysis

The effect sizes of the studies are represented with squares in the figure. The horizontal lines indicate the effect sizes in $95 \%$ confidence interval. The overall effect of the studies is represented with the shape at the bottom of the figure (Ayaz \& Söylemez, 2015). Figure 2 shows that in most of the studies, there is a medium-level negative relationship between the two variables. A positive medium-level relationship was reported only in three studies. The lower and upper confidence intervals regarding the effects sizes of individual studies reveal that all studies are within the $95 \%$ confidence level effect size intervals. Regarding the overall effect size, the lower and upper limits of confidence interval (-.430 and -.293) are within medium-level negative effect size limits based on the random effects model. 


\section{Findings Effect Size Values of the Moderator Variables}

This section includes moderator analysis findings regarding whether the effect size of the relationship between mathematics anxiety and mathematics achievement differs in terms of school level or not. The results regarding the effect size in terms of school level are presented in Table 5.

Table 5. Effect size values of the studies in terms of school level variable

\begin{tabular}{|c|c|c|c|c|c|c|}
\hline \multirow[t]{3}{*}{ School Level } & \multirow[t]{3}{*}{$\begin{array}{l}\text { Frequency } \\
\qquad(n)\end{array}$} & \multirow[t]{3}{*}{ Effect Size } & \multicolumn{2}{|c|}{$\begin{array}{l}95 \% \text { Confidence } \\
\text { Interval for Effect Size }\end{array}$} & \multirow[t]{3}{*}{$Q_{b}$} & \multirow[t]{3}{*}{$p$} \\
\hline & & & Lower & Upper & & \\
\hline & & & Limit & Limit & & \\
\hline Lower Sec. & 18 & -.384 & -.500 & -.254 & & \\
\hline High School & 8 & -.343 & -.374 & -.310 & & \\
\hline \multicolumn{7}{|l|}{ Within Groups } \\
\hline Total & 26 & -.345 & -.376 & -.313 & .388 & .534 \\
\hline
\end{tabular}

Of the 29 studies included in the meta-analysis, two are at the primary school level and one is at the university level. In the moderator analysis to find out whether effect sizes differ in terms of school levels, the studies on the primary school and the university level were not included in the analysis because there were only three of them. Eight of the studies in the data set were carried out at the high school level and 18 were at the lower secondary school level. The moderator analysis regarding the school levels revealed that there was a medium-level negative ( $r=-.384)$ relationship between mathematics anxiety and mathematics achievement at the lower secondary school level, and the relationship was significant $(p<.05)$. Regarding the studies on high school, a medium-level negative effect size was identified $(r=-.343)$ and it was significant $(p<.05)$.

A statistically significant difference could not be identified between the groups of lower secondary school and high school formed in the study $(p>.05)$. However, the level of the relationship between mathematics achievement and mathematics achievement was higher for lower secondary schools than high schools. Therefore it can be argued that the 
H. Bayırl1, M.E. Geçici, \& C. Erdem / Pamukkale University Journal of Education, 53, 87-109, 2021

negative relationship between the two variables affects lower secondary school students at a greater level than high school students.

The other moderator variable of the study is the publication type. The results regarding the effect size of the relationship between mathematics anxiety and mathematics achievement in terms of school level are presented in Table 6.

Table 6. Effect size values of the studies in terms of publication type variable

\begin{tabular}{|c|c|c|c|c|c|c|}
\hline \multirow[t]{2}{*}{ Publication Type } & \multirow[t]{2}{*}{$\begin{array}{l}\text { Frequency } \\
\qquad(n)\end{array}$} & \multirow[t]{2}{*}{ Effect Size } & \multicolumn{2}{|c|}{$\begin{array}{l}\text { 95\% Confidence } \\
\text { Interval for Effect Size }\end{array}$} & \multirow[t]{2}{*}{$Q_{b}$} & \multirow[t]{2}{*}{$p$} \\
\hline & & & $\begin{array}{l}\text { Lower } \\
\text { limit }\end{array}$ & $\begin{array}{l}\text { Upper } \\
\text { limit }\end{array}$ & & \\
\hline Thesis & 20 & -.334 & -.452 & -.205 & & \\
\hline Article & 9 & -.417 & -.463 & -.369 & & \\
\hline \multicolumn{7}{|l|}{ Within groups } \\
\hline total & 29 & -.406 & -.449 & -.361 & 1.576 & .209 \\
\hline
\end{tabular}

Of the 29 studies included in the meta-analysis, 20 are theses and nine are articles. The moderator analysis regarding the publication types revealed that there was a mediumlevel negative ( $r=-.334)$ relationship between mathematics anxiety and mathematics achievement with respect to theses and this relationship was significant $(p<.05)$. Similarly, there was a significant medium-level negative $(r=-.417)$ relationship between mathematics anxiety and mathematics achievement with respect to articles $(p<.05)$. A statistically significant difference could not be identified between the groups of theses and articles formed in the study $(\mathrm{p}>.05)$.

\section{Discussion and Conclusion}

The current study aimed to reach statistically significant results through synthesizing the research studies examining the relationship between mathematics anxiety, which is one of the critical affective factors that have an effect on mathematics achievement (McLeod, 1992), and mathematics achievement. In addition, the study also investigated whether the effect sizes of the relationship between mathematics anxiety and mathematics achievement differed in terms of school levels and publication types. The present study is limited in the 
sense that it focused on studies that were carried out only in Turkey. Besides, the study also bears the general limitations of the meta-analysis method.

This meta-analysis study involved 29 independent studies. These 29 studies had a sample of 25.704 participants in total. The heterogeneity test results indicated that the effect sizes were scattered heterogeneously ( $\left.Q=956.781 ; p=.00 ; I^{2}=\% 97.074\right)$, and Random Effects Model was preferred to calculate the overall effect size.

The meta-analysis based on the random effects model revealed a statistically significant, medium-level, and negative effect size ( $r=-.363)$ for the relationship between mathematics anxiety and mathematics achievement. In 95\% confidence interval, the lower limit of the effect size was -.430 and the upper limit was -.293 . The negative effect identified in the meta-analysis means students' mathematics achievement increases as their mathematics anxiety increases. Similarly, as their mathematics achievement decreases so does their mathematics anxiety. The effect size obtained in the current meta-analysis ( $r=-$ .363 ) is in parallel with the results of other meta-analysis studies on this issue in the literature. Ma (1999) reported a low-level negative relationship $(r=-.27)$ with 37 effect sizes ( $n=18279)$ from 26 studies. In another meta-analysis study, Zhang et al. (2019) identified a negative relationship $(r=-.32)$, which is very close to the result of this study, between mathematics anxiety and performance in mathematics using 84 effect sizes from 49 studies published between 2000-2018. Namkung et al. (2019), similarly, analyzed 131 individual studies and revealed a negative relationship $(r=-.34)$ between mathematics anxiety and mathematics performance.

A single meta-analysis study on the relationship between mathematics anxiety and mathematics achievement is available in Turkey. In their meta-analysis study, Şad et al. (2016) analyzed 11 studies that were published in Turkey between 2005-2014 from primary school level to higher education level. They reached 8327 participants through these 11 studies. They identified a medium-level negative relationship $(r=-.44)$ between mathematics achievement and mathematics anxiety and the effect size they revealed is higher than the current effect size. In the present study, in addition to 11 individual studies in the metaanalysis study by Şad et al. (2016), three studies published between 1989-2004 (Arikan, 2004; Erol, 2004; Yenilmez \& Özabac1, 2003), and two studies published between 20052014 (İlhan \& Sünkür 2013; Kalın 2010) were also added to the data set. Besides, 13 more studies published between 2014-2019 were added to the meta-analysis, and the data set 
included 29 individual studies. It can be argued that the current study extends and validates the results of the study by Şad et al. (2016).

The moderator analyses regarding the school levels revealed a statistically significant, positive, and medium level relationship between mathematics anxiety and mathematics achievement in lower secondary school level $(r=-.384, p<.05)$ and high school level $(r=-.343, p<.05)$. It is observed that the negative and medium level relationship obtained for the lower secondary school level is consistent with the studies in the literature on this school level (Baban, 2018; İlhan \& Öner-Sünkür, 2013; Luo, Wang \& Luo, 2009; K1lıç, 2011; Şentürk, 2010; Yaratan \& Kasapoğlu, 2012). The same is valid for the relationship found out in this study regarding high school level (Bakan-Kalaycıoğlu, 2015; Karlı-Şentürk, 2016; Yıldırım, 2011).

There is not a significant difference between the effect sizes of the groups formed with respect to school level $\left(Q_{b}=.388, p=.534\right)$; however, lower secondary school students' mathematics achievement is affected by mathematics anxiety at a greater level than high school students' mathematics achievement. Şad et al. (2016) identified a significant difference between lower secondary school level and high school level in their moderator analysis, and lower secondary schools were more affected in comparison to high school students. With respect to the variable of publication type, there is not a statistically significant difference between the groups of theses and articles $\left(Q_{b}=1.576, p=.209\right)$. Yet it is also observed that the relationship between anxiety and achievement is greater in articles ( $r=-.417)$ than theses $(r=-.334)$.

\section{Recommendations}

Based on the results of the current study, we offer some recommendations to researchers to study mathematics anxiety as well as teachers:

- The reasons underlying the negative relationship revealed in the current study should be studied thoroughly and some solution recommendations may be offered.

- This study focused on the relationship between mathematics anxiety and mathematics achievement based on studies that had been carried out only in Turkey. Future studies may address individual studies in the international literature.

- Meta-analysis studies on the relationship of mathematics anxiety with other variables may be carried out. 
- The results of the study suggest that teachers should plan their lessons in a way to lessen students' anxiety and they should be a guide for them to ensure students' achievement in mathematics.

Ethical Approval: Ethics committee approval was not applicable as this is a meta-analysis study, and any questionnaires or scales are not used.

Conflict Interest: Authors have no conflict of interest to declare.

Authors Contributions: The authors have contributed equally to this paper.

\section{References}

*Akgül, S. (2008). Illköğretim ikinci kademe 7. ve 8. sınıf öğrencilerinin matematik kaygıları ile algıladıkları ögretmen sosyal desteğinin cinsiyete göre matematik başarılarını yordama gücü (Unpublished Master Thesis). Yıldız Teknik University, Social Sciences Institute, İstanbul.

Ashcraft, M. H. (2002). Math anxiety: Personal, educational, and cognitive consequences. Directions in Psychological Science, 11(5), 181-185.

*Arıkan, G. (2004). Öğrencilerin matematik kaygı düzeyleri ile matematik başarı düzeyleri arasındaki ilişki -ilkögretim II. kademe- (Unpublished Master Thesis). Gazi University, Institute of Educational Sciences, Ankara.

Ayaz, M. F., \& Söylemez, M. (2015). The effect of the project-based learning approach on the academic achievements of the students in science classes in Turkey: A metaanalysis study. Education and Science, 40(178), 255-283.

Aydın, M. \& Keskin, İ. (2017). 8. sınıf öğrencilerinin matematik kaygı düzeylerinin bazı değişkenler açısından incelenmesi. Kastamonu Ĕ̆itim Dergisi, 25(5), 1801-1818.

*Baban, A. (2018). Ortaokul öğrencilerinde matematik kaygısı ve algılanan öğretmen tutumu (Unpublished Master Thesis). Nişantaşı University, Institute of Social Sciences, İstanbul.

*Bakan-Kalaycioğlu, D. (2015). The Influence of socioeconomic status, self-efficacy, and anxiety on mathematics achievement in England, Greece, Hong Kong, the 
Netherlands, Turkey, and the USA. Educational Sciences: Theory and Practice, 15(5), 1391-1401.

Bakioğlu, A. \& Özcan, Ş. (2016). Meta-analiz. Ankara: Nobel.

Baloğlu, M., \& Koçak, R. (2006). A multivariate investigation of the differences in mathematics anxiety. Personality and Individual Differences, 40(7), 1325-1335.

*Bekdemir, M. (2009). Meslek yüksekokulu öğrencilerinin matematik kaygı düzeylerinin ve başarılarının değerlendirilmesi. Erzincan Üniversitesi Fen Bilimleri Enstitüsü Dergisi, 2(2), 169-189.

Borenstein, M. (2009). Effect size for continuous data. In H. Cooper, L. V. Hedges \& J. C. Valentine (Eds.), The handbook of research synthesis and meta-analysis (2nd ed.). New York: Russell Sage Foundation.

*Bozkurt, S. (2012). Illköğretim ikinci kademe öğrencilerinde sınav kaygısı, matematik kaygısı, genel başarı ve matematik başarısı arasındaki ilişkilerin incelenmesi (Unpublished Master Thesis). İstanbul University, Institute of Social Sciences, İstanbul.

Cooper, H., Hedges, L. V., \& Valentine, J. C. (2009). The handbook of research synthesis and metaanalysis (2. Bask1). New York: Russell Sage Publication.

*Çetiner, İ. (2018). Sekizinci sınıf öğrencilerinin matematik kaygllarının temel ĕgitimden orta eğitime geçişs sınavındaki matematik başarılarına etkisi (Unpublished Master Thesis). Çanakkale Onsekiz Mart University, Institute of Educational Sciences, Çanakkale.

Dede, Y. (2016). Matematik eğitimine özgü değer kategorileri ve uygulamaları. In E. Bingölbali, S. Arslan \& İ. Ö. Zembat (Eds.), Matematik eğitiminde teoriler (pp. 785802). Ankara: Pegem A.

*Delioğlu, H. N. (2017). Sekizinci sınıf öğrencilerinin matematik başarısı ile sınav ve matematik kaygısı, matematiğe yönelik özyeterlik algısı arasındaki ilişki (Unpublished Master Thesis). Adnan Menderes University, Institute of Social Sciences, Aydın.

Dinçer, S. (2014). Eğitim bilimlerinde uygulamalı meta-analiz. Ankara: Pegem Akademi. 
Durlak, J. A., \& Lipsey, M. W. (1991). A practitioner's guide to meta-analysis. American Journal of Community Psychology, 19(3), 291-332.

*Dursun, Ş. \& Bindak, R. (2011). İlköğretim II. kademe öğrencilerinin matematik kaygılarının incelenmesi. Cumhuriyet Üniversitesi Edebiyat Fakültesi Sosyal Bilimler Dergisi, 35(1), 18-21.

Egger, M., Smith, G. D., Schneider, M., \& Minder, C. (1997). Bias in meta-analysis detected by a simple, graphical test. British Medical Journal, 315(7109), 629-634.

*Erol, E. (1989). Prevalence and correlates of math anxiety in Turkish high school students (Unpublished Master Thesis). Boğaziçi University, İstanbul.

Fennema, E., \& Sherman, J. A. (1976). Fennema-Sherman mathematics attitudes scales: Instruments designed to measure attitudes toward the learning of mathematics by females and males. Journal for Research in Mathematics Education, 7(5), 324-326.

Glass, G. V. (1976). Primary, secondary, and meta-analysis of research. Educational researcher, 5(10), 3-8.

Gürbüz, R., \& Yı1dırım, K. (2016). An investigation of mathematics anxiety of primary school teachers. Turkish Journal of Computer and Mathematics Education, 7(3), 536-552.

Haciömeroğlu, G. (2019). İlkokul öğrencilerinin teknoloji destekli matematik öğrenmeye yönelik tutum ve kaygı düzeylerinin incelenmesi. Journal of Computer and Education Research, 7(14), 356-382. DOI:10.18009/jcer.581625

Hannula M. S. (2014). Affect in mathematics education. In S. Lerman (Ed.), Encyclopedia of mathematics education (pp.23-27). Dordrecht: Springer.

Hembree, R. (1990). The nature, effects and relief of mathematics anxiety. Journal for Research in Mathematics Education, 26(1), 33-46.

Hoffman, B. (2010). "I think I can, but I'm afraid to try": The role of self-efficacy beliefs and mathematics anxiety in mathematics problem-solving efficiency. Learning and individual differences, 20(3), 276-283. https://doi.org/10.1016/j.lindif.2010.02.001

*İlhan, M. \& Öner-Sünkür, M. (2012). Matematik kaygısı ile olumlu ve olumsuz mükemmelliyetçiliğin matematik başarısını yordama gücü. Mersin Üniversitesi Eğitim Fakültesi Dergisi, 8(1), 178-188. 
*İlhan, M. \& Öner-Sünkür, M. (2013). Matematik kaygısının matematik başarısını yordama gücünün cinsiyet ve sınıf değişkeni açısından incelenmesi. Gaziantep University Journal of Sciences, 12(3), 427-441.

Kaba, Y., \& Şengül, S. (2018). The relationship between middle school students' mathematics anxiety and their mathematical understanding. Pegem Eğitim ve Ögretim Dergisi, 8(3), 599-622. http://dx.doi.org/10.14527/pegegog.2018.023

*Kalın, G. (2010). Illköğretim ögrencilerinin matematik tutumları, özyeterlikleri, kaygıları ve dersteki başarılarının incelenmesi (Unpublished Master Thesis). Başkent University, Institute of Educational Sciences, Ankara.

*Karl1-Şentürk, C. (2016). Lise ögrencilerinin matematik kaygllarının yordanması (Unpublished Master Thesis). Ahi Evran University, Institute of Educational Sciences, Kırşehir.

*Kesici, A. (2015). Ortaokul öğrencilerinin matematiğe yönelik duyuşsal özellikleri ile temel ĕgitimden ortaöğretime geçiş (TEOG) sinavları öncesi yaşadıkları stresin matematik başarısına etkisi (Unpublished Doctoral Thesis). Dicle University, Institute of Educational Sciences, Diyarbakır.

*Kılıç, A. S. (2011). İlköğretim ikinci kademe öğrencilerinin genel başarıları, matematik başarıları, matematik dersine yönelik tutumları, güdülenmeleri ve matematik kaygıları arasındaki ilişki (Unpublished Master Thesis). Gazi University, Institute of Educational Sciences, Ankara.

*Koza-Çiftçi, Ş. (2015). Effects of secondary school students' perceptions of mathematics education quality on mathematics anxiety and achievement. Educational Sciences: Theory and Practice, 15(6), 1487-1501.

*Külünk-Akyurt, G. (2019). İlkokul 4. sınıf öğrencilerinin matematik motivasyonu, kaygısı ve başarısı arasındaki ilişkinin incelenmesi (Unpublished Master Thesis). Ordu University, Institute of Social Sciences, Ordu.

Lee, O., \& Brophy, J. (1996). Motivational patterns observed in sixth-grade science classrooms. Journal of Research in Science Teaching: The Official Journal of the National Association for Research in Science Teaching, 33(3), 303-318. 
Lim, S. Y., \& Chapman, E. (2015). Identifying affective domains that correlate and predict mathematics performance in high-performing students in Singapore. Educational Psychology, 35(6), 747-764.

Luo, X., Wang, F., \& Luo, Z. (2009). Investigation and analysis of mathematics anxiety in middle school students. Journal of mathematics Education, 2(2), 12-19.

Ma, X. (1999). A meta-analysis of the relationship between anxiety toward mathematics and achievement in mathematics. Journal for Research in Mathematics Education, 30(5), 520-540.

McLeod, D. B. (1992). Research on affect in mathematics education: A reconceptualization. In D. A. Grouws (Ed.), Handbook of research on mathematics teaching and learning (pp. 575-596). New York: Macmillan.

*Mutlu, Y., Söylemez, İ. \& Yasul, A. F. (2017). İlkokul öğrencilerinin matematik kaygısı ile matematik başarıları arasındaki ilişkinin incelenmesi. Journal of Human Sciences, 14(4), 4425-4434.

Mutodi, P., \& Ngirande, H. (2014). Exploring mathematics anxiety: Mathematics students' experiences. Mediterranean Journal of Social Sciences, 5(1), 283-294. Doi:10.5901/mjss.2014.v5n1p283

Namkung, J. M., Peng, P., \& Lin, X. (2019). The relation between mathematics anxiety and mathematics performance among school-aged students: A meta-analysis. Review of Educational Research, 89(3), 459-496.

*Nazlıçiçek, N. (2007). Onuncu sınıf öğrencilerinin matematik başarılarını açıklayıcı bir model çalışması (Unpublished Doctoral Thesis). Yıldız Teknik University, Institute of Social Sciences, İstanbul.

Pajares, F., \& Graham, L. (1999). Self-efficacy, motivation constructs, and mathematics performance of entering middle school students. Contemporary Educational Psychology, 24(2), 124-139.

Pajares, F., \& Miller, M. D. (1994). Role of self-efficacy and self-concept beliefs in mathematical problem solving: A path analysis. Journal of Educational Psychology, 86(2), 193-203.

*Pekdemir, Ü. (2015). Dokuz ve onuncu sınıf ögrencilerinin matematik başarllarl ile matematik kaygıları, benlik saygıları, akademik öz-yeterlik inançları ve otomatik 
düşünceleri arasındaki ilişkiler (Unpublished Master Thesis). Karadeniz Technical University, Institute of Educational Sciences, Trabzon.

Peker, M., \& Ertekin, E. (2011). The relationship between mathematics teaching anxiety and mathematics anxiety. The New Educational Review, 23(1), 213-226.

Peker, M. \& Şentürk, B. (2012). İlköğretim 5. sınıf öğrencilerinin matematik kaygılarının bazı değişkenler açısından incelenmesi. Dumlupınar Üniversitesi Sosyal Bilimler Dergisi, 34, 21-32.

Ramirez, G., Gunderson, E. A., Levine, S. C., \& Beilock, S. L. (2013). Math anxiety, working memory, and math achievement in early elementary school. Journal of Cognition and Development, 14(2), 187-202. DOI: 10.1080/15248372.2012.664593

*Reçber, Ş. (2011). An investigation of the relationship among the seventh grade students' mathematics self efficacy, mathematics anxiety, attitudes towards mathematics and mathematics achievement regarding gender and school type (Unpublished master thesis). Middle East Technical University, Ankara.

Richardson, F. C., \& Suinn, R.M. (1972). The mathematics anxiety rating scale: Psychometric data. Journal of Counseling Psychology, 19(6), 551-554.

Sarı, M. H. \& Ekici, G. (2018). İlkokul 4. sınıf öğrencilerinin matematik başarıları ile aritmetik performanslarını etkileyen duyuşsal değişkenlerin belirlenmesi. OPUS Uluslararası Toplum Araştırmaları Dergisi, 8(15), 1562-1594.

*Sarıöl, S. (2019). The role of parental math anxiety in students' math anxiety and performance (Unpublished master thesis). Boğaziçi University, İstanbul.

Schunk, D. H. (1991). Self-efficacy and academic motivation. Educational Psychologist, 26, 207-231.

Schunk, D. H. (2005). Self-regulated learning: The educational legacy of Paul R. Pintrich. Educational Psychologist, 40(2), 85-94.

*Sezgin, M. (2007). Öğrencilerin matematik başarılarına etki eden faktörler (Unpublished Master Thesis). Beykent University, Institute of Social Sciences, İstanbul.

Sırmacı, N. (2007). Üniversite öğrencilerinin matematiğe karşı kayg1 ve tutumlarının incelenmesi: Erzurum örneklemi. Ĕgitim ve Bilim, 32(145), 53-70. 
Şad, S. N., Kış, A., Demir, M., \& Özer, N. (2016). Meta-analysis of the relationship between mathematics anxiety and mathematics achievement. Pegem Ĕgitim ve Ögrretim Dergisi, 6(3), 371-392. http://dx.doi.org/10.14527/pegegog.2016.019.

*Şentürk, B. (2010). İlköğretim beşinci sınıf öğrencilerinin genel başarıları, matematik başarıları, matematik dersine yönelik tutumları ve matematik kayglları arasındaki ilişki (Unpublished Master Thesis). Afyon Kocatepe University, Institute of Social Sciences, Afyonkarahisar.

*Temel, Z. (2018). 8. Sınıf öğrencilerinin matematiğe yönelik tutum ve kaygılarının üslü ifadeler konusundaki başarıyı yordama gücü (Unpublished Master Thesis). Necmettin Erbakan University, Institute of Educational Sciences, Konya.

Toptaş, V. \& Gözel, E. (2018). Türkiye'de matematik kaygısı ile ilgili yapılan lisansüstü tezlerin içerik analizi. Eğitim Kuram ve Uygulama Araştırmaları Dergisi, 4(3), 136146.

Üstün, U., \& Eryılmaz, A. (2014). A research methodology to conduct effective research syntheses: Meta-analysis. Education and Science, 39(174), 1-32.

Yaratan, H., \& Kasapoğlu, L. (2012). Eighth grade students' attitude, anxiety, and achievement pertaining to mathematics lessons. Procedia-Social and Behavioral Sciences, 46, 162-171.

*Yenilmez, K. \& Özabac1, N. (2003). Yatılı öğretmen okulu öğrencilerinin matematik ile ilgili tutumları ve matematik kaygı düzeyleri arasındaki ilişki üzerine bir araştırma. Pamukkale Üniversitesi Eğitim Fakültesi Dergisi, 14, 132-146.

Yetgin, O. \& Kara, A. (2018). Ortaöğretim öğrencilerinin matematik kaygısı ve öğrenmeye ilişskin tutumlarının incelenmesi. Yaşadıkça Eğitim Dergisi, 32(2), 16-27.

*Yıldırım, S. (2011). Öz-yeterlik, içe yönelik motivasyon, kaygı ve matematik başarısı: Türkiye, Japonya ve Finlandiya'dan bulgular. Necatibey Eğitim Fakültesi Elektronik Fen ve Matematik Eğitimi Dergisi, 5(1), 277- 291.

Yıldırım, N. (2014). Meta analiz. In Metin, M. (Ed.), Eğitimde bilimsel araştırma yöntemleri (pp. 137-159). Ankara: Pegem Akademi.

*Yılmaz, H. R. (2015). İlköğretim ikinci kademe ögrrencilerinde matematik başarısı ile matematik kaygısı, sınav kaygısı ve bazı demografik değişkenlerle iliş̧kisinin 
H. Bayırl1, M.E. Geçici, \& C. Erdem / Pamukkale University Journal of Education, 53, 87-109, 2021

incelenmesi (Unpublished Master Thesis). Gaziantep University, Institute of Educational Sciences, Gaziantep.

Zhang, J., Zhao, N ., \& Kong, Q. P. (2019). The relationship between math anxiety and math performance: A meta-analytic investigation. Frontiers in Psychology, 10, 1613. doi: 10.3389/fpsyg.2019.01613

(Studies marked with *are the studies included in the meta-analysis.) 